\title{
Recent Improvements in Semi-Span Testing at the National Transonic Facility (Invited)
}

\author{
G. M. Gatlin ${ }^{*}$ and W. G. Tomek ${ }^{\dagger}$ \\ NASA Langley Research Center, Hampton, Virginia, 23681 \\ F. M. Payne ${ }^{\star}$ and R. C. Griffiths ${ }^{\S}$ \\ Boeing Commercial Airplanes, Seattle, Washington, 98124
}

Three wind tunnel investigations of a commercial transport, high-lift, semi-span configuration have recently been conducted in the National Transonic Facility at the NASA Langley Research Center. Throughout the course of these investigations multiple improvements have been developed in the facility semi-span test capability. The primary purpose of the investigations was to assess Reynolds number scale effects on a modern commercial transport configuration up to full-scale flight test conditions (Reynolds numbers on the order of 27 million). The tests included longitudinal aerodynamic studies at subsonic takeoff and landing conditions across a range of Reynolds numbers from that available in conventional wind tunnels up to flight conditions. The purpose of this paper is to discuss lessons learned and improvements incorporated into the semi-span testing process. Topics addressed include enhanced thermal stabilization and moisture reduction procedures, assessments and improvements in model sealing techniques, compensation of model reference dimensions due to test temperature, significantly improved semi-span model access capability, and assessments of data repeatability.

\section{Nomenclature}

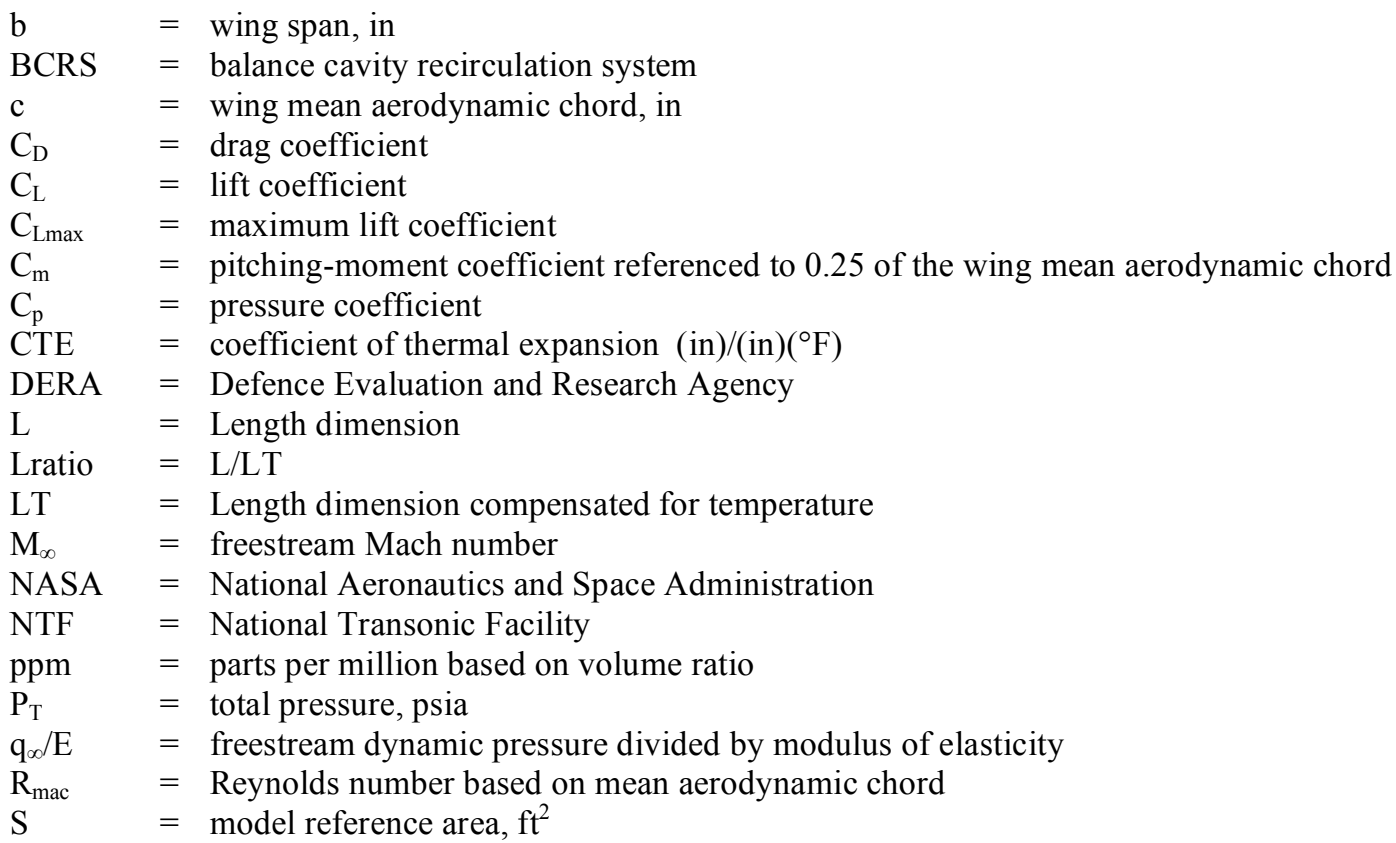

\footnotetext{
* Research Engineer, Configuration Aerodynamics Branch, Mail Stop 499, Senior Member AIAA.

${ }^{\dagger}$ Research Engineer, Configuration Aerodynamics Branch, Mail Stop 499, Member AIAA.

$\$$ Engineer/Scientist, 787 High Lift Aerodynamics, P.O. Box 3707, MC 02-XJ, Senior Member AIAA.

${ }^{\S}$ Engineer/Scientist, 787 High Lift Aerodynamics, P.O. Box 3707, MC 02-XJ, Senior Member AIAA.
} 
$\begin{array}{ll}\mathrm{T} \& \mathrm{I} & =\text { tare and interference } \\ \mathrm{T}_{\mathrm{BAL}} & =\text { balance temperature, }{ }^{\circ} \mathrm{F} \\ \mathrm{T}_{\mathrm{T}} & =\text { freestream flow total temperature, }{ }^{\circ} \mathrm{F} \\ \mathrm{T}_{\mathrm{TS}} & =\text { test section temperature, }{ }^{\circ} \mathrm{F} \\ \mathrm{X} / \mathrm{L} & =\text { longitudinal distance from fuselage nose nondimensionalized by fuselage length } \\ \alpha & =\text { angle of attack, deg }\end{array}$

\section{Introduction}

Ground-based experimentation at full-scale Reynolds numbers is now available through the use of cryogenic wind tunnels, such as the National Transonic Facility (NTF) at the NASA Langley Research Center. Most of the initial models investigated in this facility were designed and built to study the Reynolds number effects on transport aircraft utilizing a full span model installed via a typical sting arrangement. ${ }^{1-3}$ These tests were typically focused on the transonic speed regime and improving aircraft performance at the desired cruise conditions. A similar need was identified for investigating the Reynolds number effects on high-lift configurations of commercial transport aircraft operating at takeoff and approach speeds. ${ }^{4}$ However, high Reynolds numbers for these low-speed, high-lift conditions could not be attained with an appropriately scaled full span, sting mounted model. In order to achieve high Reynolds numbers for these low-speed, high-lift conditions, the test technique required the models to be halfspan, thereby allowing larger scale geometries capable of matching full-scale flight conditions (see Fig. 1). Therefore a semi-span testing capability was developed and implemented for use at the NTF. The larger model scale also offered the capability to achieve greater model fidelity relative to full-span models and the ability for stronger, stiffer models to be designed. This is an important feature for the complex, multi-component nature of high-lift configurations. In the development of an NTF semi-span testing capability, a number of investigations were conducted to address semi-span model features and testing techniques. These investigations and further discussion of the history of the semi-span test technique development can be found in references 5-8.

The objectives of the recent cryogenic semi-span wind tunnel investigations, utilizing a 5.2-percent Boeing 777200 model, were to study the effects of Reynolds number on takeoff and landing configurations of a commercial transport aircraft configuration during typical low-speed operations $\left(\mathrm{M}_{\infty}=0.26\right.$ for takeoff, and $\mathrm{M}_{\infty}=0.21$ for landing). The tests were conducted to provide a database of Reynolds number effects, up to full scale, which could be used to determine Reynolds number correlation trends, compare with actual flight test data, provide data for assessment of computational fluid dynamics (CFD) methods including turbulence modeling, and validate design and analysis methods.

This paper presents the lessons learned and improvements incorporated into the NTF semi-span testing capability as developed throughout the last three semi-span investigations. The cryogenic testing environment is the source of several of the challenges where lessons were learned and testing techniques were improved. Thermal stability of the force and moment strain gage balance as well as in the freestream flow through the test section are areas where further insights and improved capabilities have been developed. Since the test section is routinely opened for reconfigurations and model installation and removal, the level of moisture within the tunnel circuit must be carefully monitored and procedures closely followed to produce dry conditions. This is particularly important for low-speed, high-lift investigations since moisture contamination on leading-edge elements can directly affect lift coefficient. As a result, increased attention has recently been placed on the issue of moisture management. The sealing of model components to ensure there is no inappropriate leakage through wing or fuselage surfaces is another area in which lessons have been learned. Until recently the only method by which to access a semi-span model mounted in the test section was to completely open the test section with the tunnel in air mode. Needless to say, this was extremely inefficient in terms of time and cost if the tunnel was in nitrogen mode. As a result of this shortcoming, the facility model access housing used for full span, sting mounted models has been modified such that it can now accommodate semi-span models. Finally, and as always, data accuracy and repeatability are a primary concern; thus these areas will also be discussed and assessed.

\section{Experimental Approach}

\section{A. Facility Description}

The NTF is a unique national facility (Fig. 2) that enables testing of aircraft configurations at conditions ranging from subsonic to low supersonic speeds at Reynolds numbers up to full-scale flight values, depending on the aircraft type and size. The facility is a fan-driven, closed-circuit, continuous-flow, pressurized wind tunnel (Fig. 3) capable of operating in either dry air at warm temperatures or nitrogen from warm to cryogenic temperatures. When the 
tunnel is operated cryogenically, heat is removed by the evaporation of liquid nitrogen, which is injected into the tunnel circuit upstream of the fan. During this operational mode, venting is necessary to maintain a constant total pressure. When air is the test gas, heat is removed from the system by a water-cooled heat exchanger at the upstream end of the settling chamber. The test section is $8.2 \mathrm{ft}$ by $8.2 \mathrm{ft}$ in cross section and $25 \mathrm{ft}$ in length. The test section floor and ceiling are slotted (6 percent open), and the sidewalls are solid. Freestream turbulence is damped by four anti-turbulence screens and further reduced due to the 15:1 contraction ratio from the settling chamber to the test section. Fan noise effects are minimized by an acoustic treatment both upstream and downstream of the fan. The NTF is capable of an absolute pressure range from $15 \mathrm{psi}$ to $125 \mathrm{psi}$, a temperature range from $-260^{\circ} \mathrm{F}$ to $150^{\circ} \mathrm{F}$, a Mach number range from 0.2 to 1.2 , and a maximum Reynolds number of $146 \times 10^{6} \mathrm{per} f \mathrm{ft}$ at Mach 1 . Further facility details can be found in references 9 and 10 .

When conducting semi-span model investigations, a sidewall model support system is incorporated as illustrated in figure 4. The sidewall model support system is installed in the test section wall, but must be removed when full-span, sting-mounted model investigations are conducted. The semi-span model is mounted on the tunnel wall midway between the floor and ceiling, 13 feet downstream of the beginning of the test section, and is attached via adaptive hardware to the semi-span balance. The semi-span balance (Fig. 5) resides behind the tunnel wall within an insulated and heated enclosure. The nonmetric model mounting geometry, or standoff, is mounted to a wall turntable plate, which in turn is mounted to the balance housing. Thus, the standoff and model support hardware are all attached to a common model attitude drive system such that the model, standoff, balance and balance housing all rotate simultaneously as the model is moved through an angle-of-attack sweep. Further details of the sidewall model support system will be presented later when cryogenic testing issues and balance thermal stability are addressed.

\section{B. Model Description}

A 5.2-percent Boeing 777-200 semi-span model was designed and built specifically for testing in the cryogenic, pressurized conditions of the NTF such that data could be obtained up to flight Reynolds number for both takeoff and landing configurations. The fuselage was 10.7 feet long and had a maximum diameter of 13.11 inches. The wing had an aspect ratio of 8.421, a quarter-chord sweep angle of $31.64 \mathrm{deg}$, and a semi-span, b/2, of 61.438 inches. The wing leading-edge configuration consisted of inboard and outboard slats, with a seal Krueger between the flow through engine nacelle and inboard slat. The trailing-edge configuration included a double-slotted inboard flap, flaperon, outboard single-slotted flap, and aileron. No horizontal or vertical tails were used in these investigations. The model was instrumented with six chordwise rows of pressure taps on the wing as well as with substantial pressure tap coverage on the half-fuselage.

At the time the model was constructed, multiple standoff geometries were also built so the effects of variations in standoff size and shape could be investigated. Results from the standoff geometries investigation (Ref. 8) revealed that positioning the model two inches from the wind tunnel wall and using a 2-dimensional standoff produced semi-span test data that more closely correlated with full-span test data than that from any of the other standoff configurations tested. Based on these results, the 2-inch, 2-dimensional standoff has been used for all subsequent investigations. In order to minimize flow between the metric half-fuselage and the nonmetric standoff, a labyrinth seal was designed and built into these two model components. A spring-loaded Teflon seal was used on the backside of the standoff to maintain a constant seal between the standoff and the wind tunnel wall. A photograph of the model mounted in the NTF test section as investigated with the 2-inch, 2-dimensional standoff is presented in figure 6.

\section{Results and Discussion}

\section{A. Balance Thermal Stability}

An important criteria that must be satisfied in order to ensure an effective cryogenic testing capability is a thermally stable environment around the force and moment strain gage balance. When cryogenically testing fullspan, sting mounted models, the balance, which is housed within the model, is maintained at a temperature very close to the wind tunnel freestream temperature. Generally a balance cavity cooling system is used during the tunnel cool-down period to accelerate balance cooling. This procedure serves to efficiently and effectively bring the balance temperature into equilibrium with the freestream temperature. However, since the freestream, model, sting, and balance temperatures are all essentially the same this is reasonably easy to accomplish.

When testing sidewall-mounted, semi-span models, not all of the hardware components are maintained at the same temperature; therefore, maintaining a thermally stable environment around the balance presents a greater challenge. The general layout of the sidewall model support system and semi-span balance used at the NTF has 
been described above and is presented in figures 4 and 5. As can be seen from these illustrations, the sizeable sidewall balance itself, as compared to a much smaller sting-mounted balance, will require a special effort to acquire and maintain uniform temperature stability. The difficulty arises because the substantial mechanical drive system required to pitch the semi-span model, balance, and associated hardware is located within the cryogenic environment of the wind tunnel plenum. This arrangement provides the necessary mechanical pitch operations; however, associated gears and bearings must be kept warm in order to operate effectively. The requirement for the mechanical components to be kept warm, typically $95^{\circ} \mathrm{F}$, in combination with the cryogenic test condition, as cold as $-250^{\circ} \mathrm{F}$, results in an environment that is inherently thermally unstable. These two temperature extremes have previously resulted in varying thermal gradients across the sidewall balance as the semi-span model was moved through an angle-of-attack sweep. These varying thermal gradients produced varying thermal strain within the balance, which in turn resulted in unrepeatable balance data. This was clearly identified as a significant issue that had to be resolved. In order to overcome this problem, several flow-blocking seals have been added between metric and non-metric components of the model support system, and a balance cavity purge system was also implemented. The balance cavity purge system injects warm gas into the balance cavity at the non-metric end of the balance so as to prevent cold gas from the test section from entering the opposite end of the balance cavity. The results of these test technique enhancements were proven effective and are presented in reference 8 .

Since these enhancements have been incorporated, another improvement has been added to the sidewall model support system. This improvement, referred to as the Balance Cavity Recirculation System, or BCRS, was installed as a replacement for the balance cavity purge system noted above. The new BCRS, illustrated in figure 7, was designed to not only inject warm gas into the balance cavity, but to also reheat and recirculate this warm gas such that the sidewall balance will be maintained at a uniform temperature no matter what the test section test conditions are. This "closed loop" system was designed and installed to provide a more efficient and effective system than the previous balance cavity purge system. It should be noted it is the combined effects of the addition of the multiple flow-blocking seals and the BCRS together that have produced a very effective capability to provide and maintain a thermally stable environment for the balance. All of these modifications and additions to the sidewall model support system are identified by the red text in the diagram presented in figure 7.

Obtaining and maintaining a homogeneous thermal environment around the sidewall balance has been very effectively accomplished due to the enhancements noted above, and balance temperature data illustrating this are presented in figure 8. The temperature data presented are from the top, middle, and bottom of the balance at three spanwise locations: the non-metric end, the center strain gage section, and the metric end. Upon examination of these data it is noted the maximum variation in temperature across the balance is no greater than $2.5^{\circ} \mathrm{F}$. This continues to hold true as the wind tunnel test condition is changed from $-250^{\circ}$ to $-218^{\circ}$ to $-168^{\circ} \mathrm{F}$. Thus a thermally stabilized balance has been achieved and maintained across a range of test temperatures.

\section{B. Wind Tunnel Flow Thermal Stability}

Just as balance thermal stability is important to ensure accurate and repeatable test data, so is the thermal stability of the wind tunnel flow. Due to the substantial thermal mass of the wind tunnel structure, it is important to ensure adequate tunnel conditioning time is allowed when setting a new temperature test condition. This is required so the freestream flow in the test section will be as thermally uniform and stable as possible before data collection is initiated. Thus in order to assess the thermal stability of the flow through the test section, temperature data were obtained at the following locations: just upstream of the test section, at the tunnel floor and ceiling within the test section, and on the model itself. The temperatures measured just upstream of the test section were measured on each of the tunnel walls two feet upstream of the beginning of the test section. Two surface temperatures were measured on each wall with each measurement location being 24.25 inches from one of the respective corners. The temperature measurements on the floor and ceiling within the test section were obtained from probes inserted approximately one inch through the slot on the model side of tunnel centerline at a location 25.25 inches back from the start of the test section. The model temperatures were measured inside the fuselage at a forward, mid, and aft location. A fourth model temperature was measured on the inboard forward portion of the wing spar. Data from all these temperature measurement locations are presented together for six back-to-back runs in figure 9. Data from the first three runs were obtained at a test condition of $-250^{\circ} \mathrm{F}$, data from the next two runs were obtained at a test condition of $-218^{\circ} \mathrm{F}$, and data from the last run were obtained at a test condition of $-168^{\circ} \mathrm{F}$. Observation of these data indicate a maximum temperature range on the order of $13^{\circ} \mathrm{F}$ for the data obtained at the $-250^{\circ} \mathrm{F}$ test condition. It would be expected the range of temperatures would be the largest for this coldest test condition. When the test condition was warmed up to $-218^{\circ} \mathrm{F}$ the temperature range was reduced to approximately $11^{\circ} \mathrm{F}$, and when the test condition was warmed up to $-168^{\circ} \mathrm{F}$ the temperature range was further reduced to approximately $9^{\circ} \mathrm{F}$. These data are representative of the temperature ranges that can be expected to be maintained at the test temperatures indicated. 
The important point to be noted is that the temperatures are stable prior to starting a run series, and that the temperatures remain stable throughout the run series.

In order to achieve and maintain a desired test condition in as efficient a manner as possible when operating at cryogenic conditions, it is important to produce a thermally stable freestream flow through the test section in as short a timeframe as possible. Some techniques and procedures have been developed to aid in the process of reducing the time required to arrive at the desired test condition, and they are presented as follows. The first technique to be addressed is referred to as plenum venting. In the normal cryogenic operation of the NTF, the injection and evaporation of liquid nitrogen into the tunnel circuit to reduce tunnel temperature simultaneously increases tunnel pressure, thus resulting in the need to vent the tunnel if the desire is to maintain a constant tunnel pressure. Thus if undesirable temperature gradients exist, the logical procedure would be to reduce tunnel pressure by venting the tunnel in an area where the warmest gas can be removed. Since the goal is to produce as thermally uniform a flow as possible through the test section, the most beneficial location to vent pressure from the tunnel would be from the top of the plenum surrounding the test section. Since venting of the tunnel was originally not available from the top of the plenum, this capability has been added, and in turn used effectively to reduce thermal gradients in the flow through the test section.

Another technique implemented to reduce thermal gradients in the test section flow has been the use of the semi-span model itself to stir or mix the flow. Setting the model at a moderate to high angle of attack, approximately $5^{\circ}$ below the angle of attack for $C_{\mathrm{Lmax}}$, will act to deflect the warmer flow in the upper portion of the test section down into the cooler flow below. This can help to reduce the thermal gradient that begins to form in the test section as the tunnel cooldown procedures are conducted. The intent of keeping the model at an angle of attack below $\mathrm{C}_{\mathrm{Lmax}}$ is simply to avoid any undue model fatigue that could be generated by prolonged operations at an angle near the stall angle of attack. A variation of this flow-stirring technique that has also been effective in reducing thermal gradients in the test section is to simply pitch the model through a full angle of attack sweep without taking any test data prior to the first data run.

A part of the test procedure that has been determined to directly affect thermal gradients in the test section is the point at which a wind-off zero is taken. Since a wind-off zero data point is a necessary part of the data taking process, it is important to understand the effects it has on the thermal gradient in the test section flow. It has been observed that if the above mentioned efforts have successfully minimized thermal gradients in the test section flow, the process of bringing the tunnel flow to zero velocity in order to obtain a wind-off zero data point just prior to initiating a run series will have a negative impact. Bringing the tunnel flow to zero velocity will allow the thermal gradient in the test section to readily expand. This will result in additional time and nitrogen required to again reduce the magnitude of the test section thermal gradient prior to taking wind-on data. Thus the time for a wind-off zero data point to be taken is at the end of the run series.

A final technique implemented to reduce thermal gradients in the test section flow is simply to monitor the temperatures referred to above and presented in figure 9. Allowing enough time to ensure the freestream flow temperature in the test section and the temperatures recorded on the model have stabilized prior to acquiring test data is an important step in the process to obtaining accurate and repeatable test data.

\section{Moisture Management}

An important issue to keep in mind during the operation of any cryogenic wind tunnel facility is the requirement to prevent the tunnel flow from becoming contaminated with moisture. The specific problematic issue resulting from moisture contamination is the formation of frost on the model surfaces during cryogenic operations. This obviously results in an uncontrollable and undesired variation to the model geometry. This is particularly true for the highly polished surface finishes typical of cryogenic, high Reynolds number models. Low-speed test conditions, coupled with highly polished high-lift wing elements and associated high suction peaks, result in high Reynolds number, high-lift, semi-span testing operations being particularly sensitive to any sort of frost contamination. In general, the test velocity, or Mach number, can also be a factor in the formation of frost on the model. In transonic testing, any frost that might form on the model during wind-off or low-speed operations could possibly be scrubbed off the model at transonic speeds. However, when investigating high-lift configurations at takeoff and approach conditions, it is generally not possible to increase the freestream velocity to a high enough value to eliminate frost on the model. Leading- and trailing-edge high-lift devices are generally not able to withstand the loads generated at the higher speeds necessary to scrub frost off the model. It could be argued that high-lift elements could be the most sensitive of all to frost contamination; however, the primary goal, as far as frost is concerned, is to operate the facility so it is not possible for frost to form on any model under any test condition.

Since the NTF was designed for both air and nitrogen operations, it is typical for the facility to conduct tunnel drying procedures in the air mode of operation prior to converting to the nitrogen mode of operation. This is 
particularly true if the test section has been open for any length of time, as is the case when the sidewall model support system is installed in the test section just prior to a semi-span model investigation. Operational experience has shown that running the tunnel in air mode will serve to reduce the moisture content within the tunnel circuit. Moisture reduction occurs as the dry airflow through the tunnel draws out residual moisture that can reside in the tunnel insulation lining the inside of the tunnel circuit. Thus in preparation for cryogenic operations, running the tunnel in air mode in conjunction with multiple pressurizing and venting cycles is the first step in reducing the moisture content within the tunnel circuit. The effectiveness of this is, of course, directly related to the moisture content of the air being pumped into the tunnel. As a result, an active air-drying system has been implemented at the NTF so that each time the tunnel circuit is vented down the tunnel is re-pressurized with the driest air possible. This recent improvement to the NTF has effectively enhanced the ability to reduce moisture content in the tunnel circuit. Since the insulation lining inside the tunnel circuit can hold moisture, it is critical to eliminate as much moisture from it as possible prior to converting to nitrogen operations. Current procedures call for pressurizing and venting the tunnel circuit multiple times while in air mode with the goal of reducing the moisture content to less than 20 $\mathrm{ppm}$, based on volume. Once this level of moisture is attained, and maintained, the facility is ready to convert from air to nitrogen as the test gas. The process of converting from air to nitrogen, which consists of pressurizing with nitrogen and venting in several cycles, results in an even lower moisture content within the tunnel. Once the tunnel circuit has been completely exchanged into nitrogen, the goal is a moisture content of less than $10 \mathrm{ppm}$, while still at ambient temperature. If this moisture level has not been attained, then further pressurizing and venting of the tunnel must be conducted. However, due to the cost of nitrogen, it is obviously much more preferable to effectively reduce the tunnel moisture while in the air mode of operation. Finally, when reducing tunnel temperature to engage in cryogenic operations the tunnel moisture level goal is to be less than $1 \mathrm{ppm}$. A graph illustrating this moisture reduction process is presented in figure 10. As long as tunnel operations continue in nitrogen mode at pressures above atmospheric the moisture content within the tunnel should not increase.

\section{Access Housing Enhancement}

During any wind tunnel investigation easy access to the model in the test section is important due to the typical need for model configuration changes. When testing cryogenically with nitrogen as the test gas, access to the model is not trivial and requires special attention. When testing full-span, sting mounted models at the NTF, a model access system is used in which a rectangular access housing or tube is inserted from each side of the tunnel such that the model is captured within the housings when they meet and seal together at the center of the test section. ${ }^{9}$ This allows access to the model within an air filled chamber while the rest of the tunnel circuit remains filled with nitrogen and at cryogenic temperatures. This system has worked well for full-span, sting mounted models, but in its original design could not provide access to sidewall mounted semi-span models. Until recently, if a semi-span model access was required during cryogenic operations, the entire tunnel circuit would need to be warmed up, evacuated of nitrogen, and converted back to air. Since that was extremely inefficient in terms of time and cost the existing model access system has been modified to allow access to sidewall mounted semi-span models as well. This was accomplished by extending the length of one access housing and designing the end of the extension such that it would effectively seal to the sidewall on which the semi-span model was mounted. Due to the streamwise location of the access housing, in order to capture sting mounted models, and due to the 10.7 foot length of the 777 semi-span model, the downstream vertical wall of the extended access housing will come in contact with the aft portion of the half-fuselage. This issue however, has been overcome by simply designing a customized seal cut to fit the local contour of the fuselage at the location where the fuselage and access housing meet. A photograph showing the extended access housing encompassing the semi-span model and sealed against the tunnel sidewall and aft fuselage is presented in figure 11. This enhanced model access system has been used successfully and demonstrated to provide effective semi-span model access during cryogenic operations.

During this initial operation of the sidewall model access system, a part of the operational process was to ensure the wind tunnel sidewall was at a temperature above freezing prior to inserting the access housing. This was done to prevent moisture introduced by personnel working on the model from ending up as frost on the model or tunnel sidewall. This process was effective, however, at the expense of a considerable amount of time required to warm the tunnel sidewall to a temperature above freezing. Recognizing this as a time intensive and inefficient process, a second enhancement to the sidewall model access system, designed to address this issue, is currently underway. This additional modification will incorporate an insulating wall or blanket to cover the portion of the tunnel sidewall exposed within the access housing. The intent of this new feature is to allow access to the model while testing at temperatures as low as $-250^{\circ} \mathrm{F}$, without requiring the tunnel sidewall to be warmed up above freezing. The insulating blanket will be attached to the end of the access housing that contacts the tunnel sidewall and will have a pass-through hole cut in it the shape of the model side profile. A dry air purge system will also be included to 
eliminate the nitrogen gas captured between the insulating blanket and the tunnel sidewall when the access housing is inserted. The semi-span model itself will of course still need to be warmed prior to initiating any model work, however the overall time required to gain access to the model will be greatly reduced.

\section{E. Thermal Compensation of Model Reference Dimensions}

Due to the extreme range in operational temperatures, $-260^{\circ}$ to $+150^{\circ} \mathrm{F}$, at the National Transonic Facility, it is recognized the model being tested can change in size due to thermal expansion or contraction. Although the actual maximum change in size of the model is only on the order of 0.1 percent based on length, this will affect the aerodynamic coefficients. Since this model size variation can easily be accounted for, the appropriate equations to compensate for the thermal effects have been developed and implemented into the NTF data reduction process.

It is noted that model size variation due to thermal expansion or contraction has been previously addressed at the NTF over ten years prior. However, due to emphasis at that time on transonic cruise investigations, thermal compensation corrections were shown to have very minor effects on the aerodynamic coefficients and thus were not implemented. Thermal compensation corrections will have a larger effect on the much higher lift coefficients generated by high-lift configurations, thus it was decided thermal compensation corrections should now be accounted for.

Since the semi-span model used in recent investigations, along with many other cryogenic models investigated at the NTF, was fabricated from Vascomax C-200 maraging steel, the coefficient of thermal expansion for this material was required. Based on material characteristics presented in reference 11, the following equation for the coefficient of thermal expansion as a function of freestream total temperature was developed.

$$
\mathrm{CTE}=\left(3.475 \times 10^{-9} * \mathrm{~T}_{\mathrm{T}}\right)+4.502 \times 10^{-6}(\mathrm{in}) /(\mathrm{in})\left({ }^{\circ} \mathrm{F}\right)
$$

The next step was to use the coefficient of thermal expansion, for the appropriate test temperature, to determine the corresponding linear variation of a particular model dimension. The temperature compensated length, LT, is given by the following expression.

$$
\mathrm{LT}=\left[\left(\mathrm{T}_{\mathrm{T}}-70\right) * \mathrm{CTE}\right] * \mathrm{~L}+\mathrm{L}
$$

The variable $\mathrm{L}$ is an original length dimension for an ambient temperature of $70^{\circ} \mathrm{F}$. It should be noted that equation (2) is referenced to an ambient temperature of $70^{\circ} \mathrm{F}$, thus model dimensions will increase for temperatures above $70^{\circ} \mathrm{F}$ and decrease for temperatures below $70^{\circ} \mathrm{F}$. Once the temperature compensated length is known, the parameter Lratio, as defined below, is determined.

$$
\text { Lratio }=\mathrm{LT} / \mathrm{L}
$$

Lratio or (Lratio $)^{2}$ is then multiplied by linear or area dimensions respectively to determine the corresponding thermally compensated values. Thus model reference dimensions such as $\mathrm{c}, \mathrm{b}$, and $\mathrm{S}$ can be corrected due to temperature, and in turn can be used to provide thermally compensated aerodynamic coefficients. It is noted that although this correction is appropriate, it is an approximation. The factors resulting in the approximation are that the model is not entirely made of Vascomax and the equations are based on an equivalent flat plate.

\section{F. Model Sealing}

Any unintentional flow path into or through a wind tunnel model will distort the true localized flow field leading to the potential for erroneous results. Especially of concern is leakage through the wing from the lower surface to the upper surface. In the course of our recent high-lift, semi-span model investigations some evidence was noticed that indicated a possible leakage was present through the wing main element. Even though the model was precisely fabricated for a very tight fit between assembled components, a completely airtight seal was not likely present. A photograph showing evidence of a flow path through the wing is presented in the top portion of figure 12. What can be seen here is some residual light oil, originally used to preserve the model surfaces during storage that has seeped out from between the assembled model components on the wing upper surface during wind-on testing. As shown in the illustration, this model part line is in the region of the pressure peak on the wing, thus it is interpreted that the substantial low pressure in combination with an extremely small gap between the model components and some residual light oil in the gap has resulted in the oil following a flow path between the model components up to the part line visible on the wing upper surface. This potential for a venting of the high pressure 
region below the wing to the low pressure region above the wing could lead to data indicating an underperformance of the lift generating characteristics of the wing.

As a result of concerns about the potential for leakage or venting through small gaps present where model components are assembled together, model component sealing has been more carefully addressed. It is quite common for models of high-lift configurations to be designed with a central wing spar and alternate leading-edge and trailing-edge assemblies. Thus when these components are bolted together, a sealant should be applied on the internal mating surfaces in order to prevent any possible flow between the parts as illustrated in figure 12. A sealant, such as Xantopren or Examix, has been used effectively in this application. This sealant can be prepared and applied as a thin mixture, allowing it to be very compressible, and therefore well suited for use with tightly fitting model components. This sealant works well when compressed between model parts that are bolted together. However it has no adhesive characteristics. Other sealing substances such as RTV have been used effectively in areas where an adhesive characteristic in the sealant is desired. An example of this would be where pressure tubing from a flap assembly passes through an opening in the fuselage side of body. An adhesive characteristic is necessary here so the seal remains intact. An associated lesson learned, with respect to sealing model components, is that during cryogenic operations a contraction of the assembled model can lead to a squeezing and protruding of the sealant such that it could extend out and above the local model contour. This is obviously undesirable and therefore must be guarded against. One way to prevent this is to apply sealant in small amounts on internal mating surfaces such that the sealant cannot extend up to the external flow surface. This issue will generally need to be assessed for each unique application due to internal cavities, fastener locations, channels for instrumentation routing, etc.

Another important area of model sealing, somewhat unique to semi-span models, is the seal between the metric fuselage and the non-metric standoff. Due to the necessity of a non-contacting seal between these metric and nonmetric components, a labyrinth seal design has been used (see Fig. 13). The nature of this seal design has conflicting requirements in that the metric and non-metric components can not touch or "foul," while at the same time the goal is to prevent as much flow as possible from passing through. This results in minimizing the gap between the two sides of the seal, while at the same time ensuring there is enough space so contact will not occur during wind-on testing. In some earlier semi-span test technique development work ${ }^{8}$ investigations were conducted to determine if there was a need at all for a labyrinth seal. These results indicated however, that if no attempt was made to block the flow between the fuselage and the standoff, the aerodynamic characteristics of the configuration were quite adversely affected, especially in the region of maximum lift. The labyrinth seal shown in figure 13 was therefore designed with the smallest gap deemed acceptable such that no contact would occur during wind-on testing.

One question that has arisen about the effectiveness of the labyrinth seal between the fuselage and standoff is if there is any variation in its effectiveness based on Reynolds number. This is important since a primary goal of our investigations is to assess Reynolds number effects on a particular model configuration. In order to address this issue, pressure measurements were made along the length of the flat side of the fuselage between the fuselage and standoff at Reynolds numbers up to 24 million. These pressure data are presented in figure 14 for a low and high Reynolds number (5.95 and 24 million) and for angles of attack of $6.4^{\circ}$ and $16.4^{\circ}$. As can be seen from the data presented, there is essentially no noticeable variation with Reynolds number and only a very slight variation with angle of attack. Some variation in seal effectiveness due to angle of attack might be expected, due to a substantially increased pressure differential above and below the model as angle of attack is increased for a high-lift configuration. It is encouraging to note however, that Reynolds number effects identified on the model configuration being investigated are not influenced by any Reynolds number effects on the labyrinth seal performance.

\section{G. Improved Data Repeatability}

During any experimental investigation it is always important to understand the levels of uncertainty in the data being obtained. One way to assess the levels of uncertainty is to take multiple sets of data under the same conditions so an assessment of repeatability can be made. If there is a substantial amount of variation in the data, then there is some undesirable variation in the test process that should be eliminated. As indicated earlier, three semi-span investigations have recently been conducted with improvements to the test process being implemented after each investigation. In order to assess recent improvements in data repeatability levels due to enhancements to the semispan test process, data repeatability plots have been prepared for the last two semi-span investigations. These data were obtained for the model in the landing configuration, at an extreme test temperature of $-249^{\circ} \mathrm{F}$, and are presented in figure 15. The delta values presented represent the difference between the data at a given angle of attack and the average data value at that angle of attack. The solid lines represent the 95 -percent confidence interval 
of the finite data sample. The 95-percent confidence interval can be interpreted as the bounds about the estimated mean that encompass the true mean value, with a chance of 95-percent. A more in-depth description of the confidence interval and the methods used to calculate it are presented in references 12 and 13 . The first plot (Fig. 15 (a)) was prepared with data from the second to last semi-span investigation, test number 145, while the second plot (Fig. 15 (b)) was prepared with data from the last semi-span investigation, test number 150 . In both cases the first three runs were obtained back-to-back within a series, and the remaining runs were obtained back-to-back within another series run later in the test. It is normally anticipated that back-to-back repeatability will indicate small variations due to a very short timeframe between the repeat runs, however longer term repeatability can be more of a challenge since there is a wider opportunity for something unintended to change. Since each plot in figure 15 is comprised of data obtained during two different series at two different times during the respective wind tunnel test, an indication of within test long-term repeatability is represented. Repeatability goals, as identified in reference 14 , are indicated for each coefficient on the right-hand side of figure 15 (b).

The two sets of data presented from test 145 were separated by several runs at warmer temperatures as well as by a complete tunnel warm-up to ambient temperature. One run at a higher than typical dynamic pressure of $474 \mathrm{psf}$ was also conducted between the two run sets. The ideal situation would be for all five of these runs to produce the identical set of data. If that were the case, then our test process for test 145 would have been demonstrated to be repeatable. Examination of these data however, indicate our process was not repeatable. It is clearly seen that data from the first three runs are grouped together, and data from the last two runs are grouped together. This indicates something is inconsistent from the first series to the second series. When the repeat data from test 150 are examined, a much improved level of repeatability is observed. The two sets of data presented from test 150 were also separated in time by several runs at warmer temperatures; however, in this case the tunnel was warmed to ambient temperature, an aileron deflection angle was changed, testing was conducted at cryogenic temperatures as cold as $-250^{\circ} \mathrm{F}$, the tunnel was again warmed to ambient temperature, the aileron deflection angle was changed back, and then the original data set was repeated. Thus in this sequence of testing, there were more test parameter variations between the two run sets than was the case for the repeat runs presented for test 145 . From this perspective one could argue that data repeatability was a greater challenge for the test 150 data set. It is difficult to prove the exact reason or reasons for the poor cross series data repeatability shown in the test 145 data as compared to the test 150 data; however, there are three items that are likely to have contributed to this situation. The first is that in test 145 temperature instrumentation had not yet been installed on the tunnel walls just upstream of the test section and thus thermal stability of the freestream flow through the test section was not sufficiently monitored prior to data acquisition. As a result, inconsistent thermal variations from one run set to another were quite possible. Thermal stability of the flow through the test section was much more carefully monitored in test 150 as described earlier in this paper. The second possible contributor to the variation is the fact that a high dynamic pressure run was conducted between the run sets in test 145, but not in test 150. This higher loading of the model, although within the model design limits, may have caused some small variation in the model geometry leading to a shift in the data generated. The third possible contributor, which may have been enhanced by the high dynamic pressure run, was that the sealing of model components, as described earlier, was not done during the model assembly for test 145 , where it was done in test 150 . Whatever the cause, the two separate data groups shown in the test 145 data indicate that either test conditions, or model geometry, or both were not the same in the two run series. It should be noted for all repeatability data presented that due to the inherent dynamics of the separated flow at and beyond the stall angle of attack, as well as at negative angles of attack, the 95-percent confidence interval expands greatly, as expected, at these conditions.

The final assessment in this discussion of data repeatability is that the efforts to identify and carefully follow a consistent test process have resulted in the demonstration of an improved level of data repeatability. Within test data repeatability has also been shown to be within our requirements for attached flow conditions. Ensuring the balance, model, and freestream flow are all thermally stable prior to data acquisition, as well as sealing all model components upon assembly has lead to a clear improvement in overall data quality.

\section{H. Wind Tunnel to Flight Correlation}

An important part of our assessment of the high Reynolds number semi-span testing capability is to compare data obtained up to flight Reynolds number with actual flight data. In order to address this issue, maximum lift coefficient data for the takeoff configuration are presented in figure 16 for Reynolds numbers of 6.85 million up to 27.48 million. These data are presented with flight test data, as well as with data previously obtained at 6.85 million Reynolds number from a full-span investigation in the DERA (now QinetiQ) 5-Meter wind tunnel in Farnborough, England. It is shown that the NTF test data matches the full-span DERA test data very well, and as Reynolds number is increased, the data progresses along the trend line up to the flight test Reynolds number. A repeat series 
of data are also presented, showing good correlation with the initial series, but with a slightly larger variation at the flight Reynolds number. These data are quite encouraging in that they follow the expected trend with increasing Reynolds number and they fall within the anticipated flight test data error band. Thus the high Reynolds number semi-span test capability at the NTF can effectively provide trends up to flight Reynolds number and is shown to provide good correlation with flight test data.

\section{Conclusions}

The development and improvement of a low-speed, high Reynolds number semi-span test capability at the NTF has been driven by the need for a flight Reynolds number, ground based test capability to support the design and development of advanced subsonic transport high-lift systems. Throughout recent semi-span investigations multiple lessons have been learned, and in turn improvements incorporated into the semi-span test process. The following insights and enhancements have resulted in recent improvements to the NTF semi-span test capability.

1) Maintaining thermal stability of the strain-gage balance while operating from ambient to cryogenic freestream temperatures is essential to ensure data quality. The incorporation of a balance cavity recirculation system, along with several other insulating devices, into the NTF sidewall model support system has been shown to very effectively satisfy this requirement.

2) Obtaining and maintaining thermal stability of the flow through the test section is also essential to ensure data quality. Processes to reduce test section thermal gradients in coordination with careful monitoring of the test section freestream temperature have effectively provided freestream flow thermal stablility.

3) Effective moisture management is essential to prevent model surface contamination at cryogenic test conditions. Operating procedures have been developed that will satisfy this requirement by producing a moisture content of less than 1 part per million during nitrogen operations.

4) A semi-span model access capability has been developed that greatly improves test efficiency by eliminating the need to convert the tunnel circuit from nitrogen back to dry air in order to access the model.

5) Improved testing capabilities and processes have resulted in improved data repeatability and an effective correlation with flight data.

\section{Acknowledgments}

The authors would like to express their sincere appreciation for the dedicated efforts of the many individuals who have diligently worked to develop and improve the NTF semi-span testing capability. Numerous NASA and contractor personnel associated with the NTF have provided valuable insights and feedback in regard to improvements to model installation and access, instrumentation, data reduction, and tunnel operational processes. Numerous personnel from the Boeing Company have supported all phases of these investigations and have also provided valuable insights from a customer perspective. The collective efforts of all involved have produced substantial progress toward our common goal.

In particular the authors would like to recognize the following individuals and organizations for important contributions in critical areas: Allen Kilgore and David Tuttle for their continual and dedicated efforts to carefully monitoring and effectively reducing moisture within the NTF tunnel circuit; Dr. Balakrishna and David Butler for the design and development of a balance cavity recirculating system to effectively control and maintain a uniform sidewall balance temperature; Allen Kilgore, John Meador, and Arbria Wright for their diligent and thorough design and implementation of a semi-span model access system; Richard Wahls for his insights and guidance on the thermal compensation correction for model reference dimensions; and the staff of the European Transonic Wind Tunnel (ETW) for the development of the model component sealing procedure and for sharing insights and techniques used to produce a thermally stable tunnel flow.

\section{References}

${ }^{1}$ Campbell, J. F., “The National Transonic Facility - A Research Perspective,” AIAA Paper 84-2150, August 1984.

${ }^{2}$ Wahls, R. A., "The National Transonic Facility: A Research Retrospective," AIAA Paper 01-0754, January 2001.

${ }^{3}$ Luckring, J. M., "An Overview of National Transonic Facility Investigations for High Performance Military Aerodynamics," AIAA Paper 01-0906, January 2001.

${ }^{4}$ Lynch, F. T., "Experimental Necessities for Subsonic Transport Configuration Development," AIAA Paper 92-0158, January 1992.

${ }^{5}$ Milholen, W. E., II, Chokani, N., and McGhee, R. J., "Development of Semispan Model Test Techniques," Journal of Aircraft, Vol. 33, No. 6, 1996, pp. 1115-1122.

${ }^{6}$ Gatlin, G. M., and McGhee, R. J., "Experimental Investigation of Semispan Model Testing Techniques," Journal of Aircraft, Vol. 34, No. 4, 1997, pp. 500-505. 
${ }^{7}$ Milholen, W. E., II, “Design Methodology for Semispan Model Mounting Geometries,” AIAA Paper 98-0758, January 1998.

${ }^{8}$ Gatlin, G. M., Parker, P. A., and Owens, L. R., Jr., "Advancement of Semispan Testing at the National Transonic Facility," Journal of Aircraft, Vol. 39, No. 2, 2002, pp. 339-353.

${ }^{9}$ Fuller, D. E., "Guide for Users of the National Transonic Facility," NASA TM-83124, 1981.

${ }^{10}$ Gloss, B. B., "Current Status and Some Future Test Directions for the US National Transonic Facility. Wind Tunnels and Wind Tunnel Test Techniques," Royal Aeronautical Society, 1992, pp. 3.1-3.7.

${ }^{11}$ Wigley, D. A., "Materials and Techniques for Model Construction," NASA CR-172620, 1985.

${ }^{12}$ Coleman, H. W., and Steele, W. G., Jr., Experimentation and Uncertainty Analysis for Engineers, Wiley, New York, 1989, pp. 24-30.

${ }^{13}$ Wahls, R. A., Adcock, J. B., Witkowski, D. P., and Wright, F. L., “A Longitudinal Aerodynamic Data Repeatability Study for a Commercial Transport Model Test in the National Transonic Facility," NASA TP-3522, 1995.

${ }^{14}$ Payne, F. M., "Low Speed Wind Tunnel Testing Facility Requirements: A Customer's Perspective," AIAA Paper 99-0306, January 1999. 


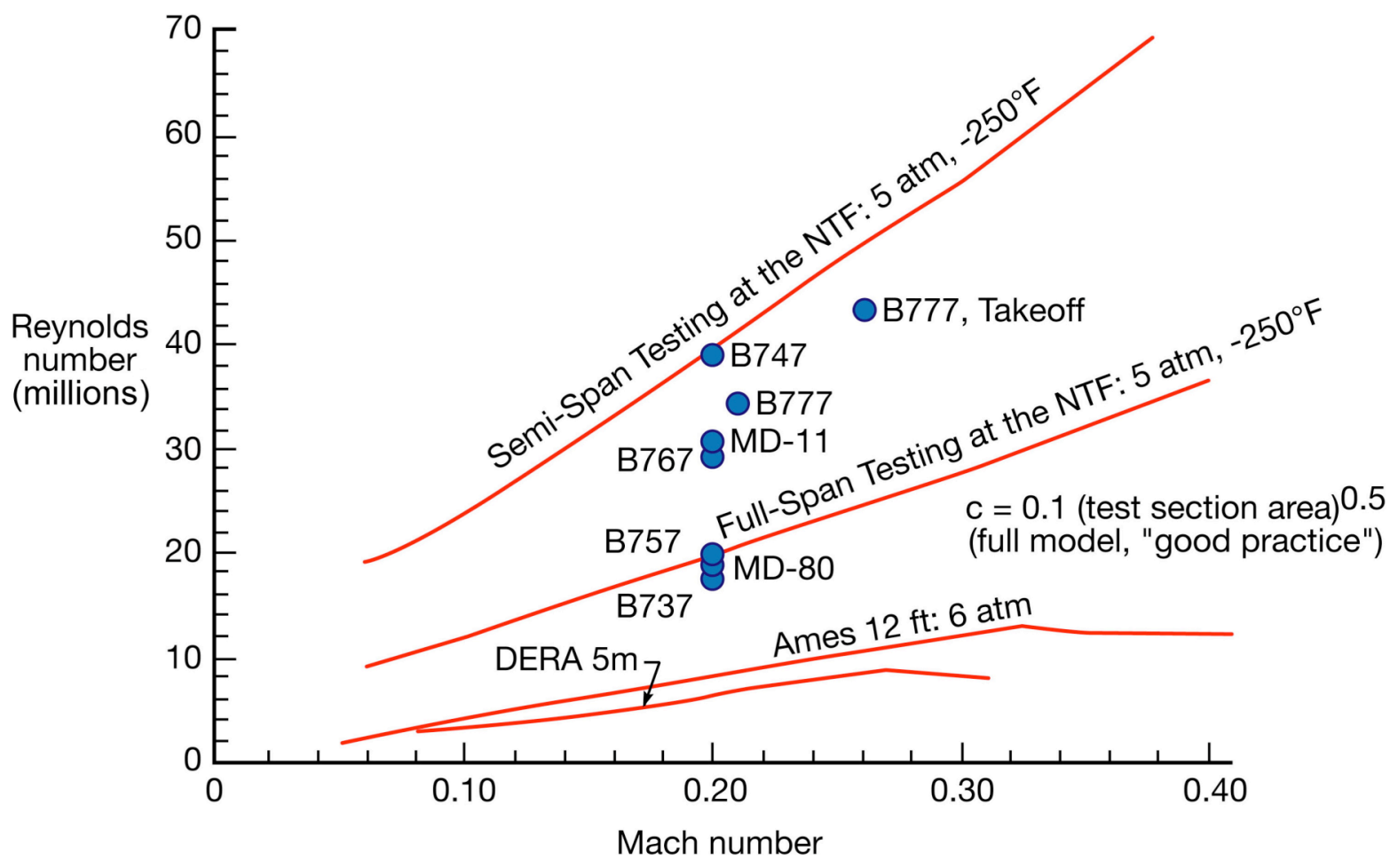

Figure 1. Low-speed, high Reynolds number test capabilities.

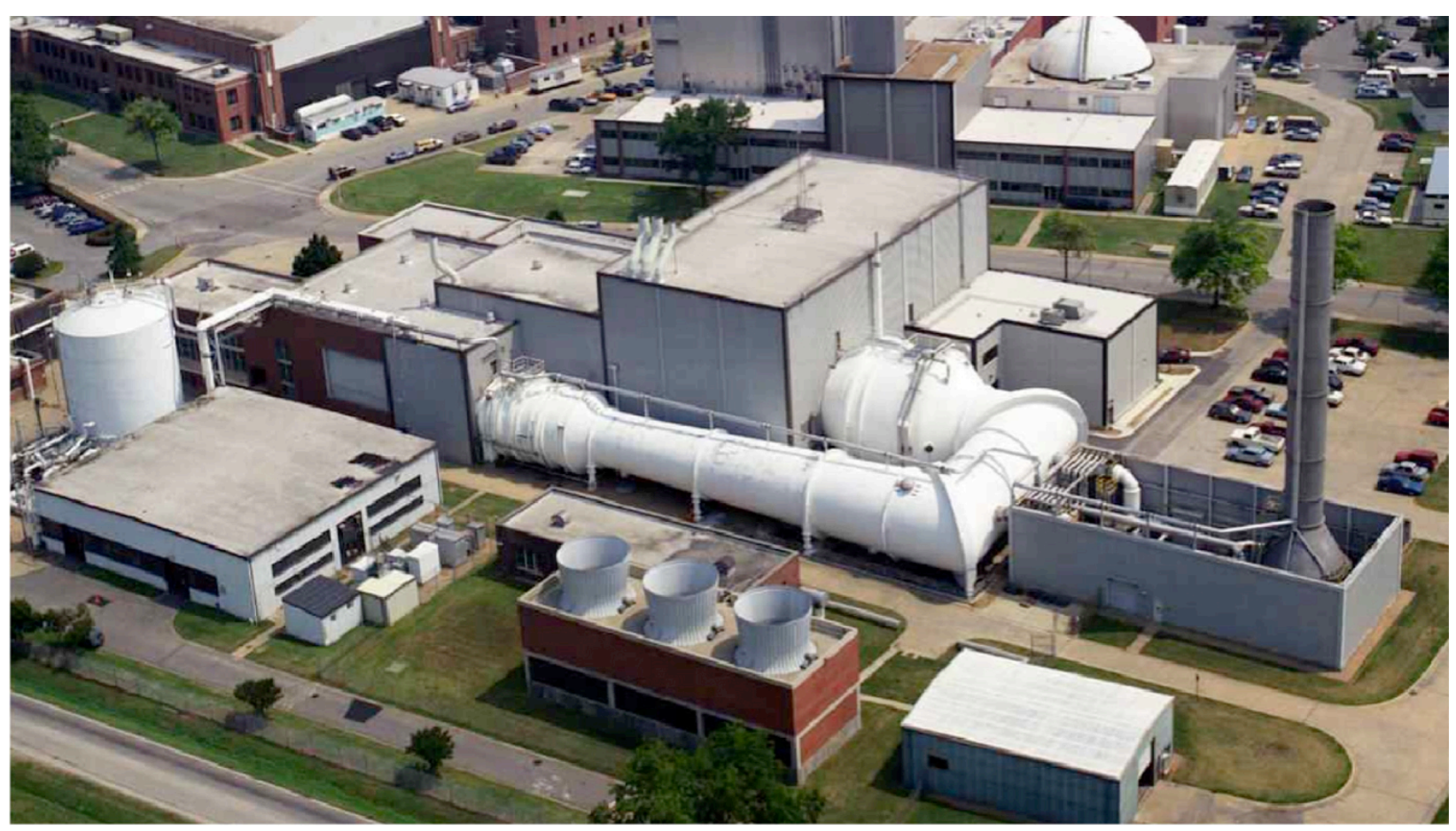

Figure 2. External view of the National Transonic Facility. 


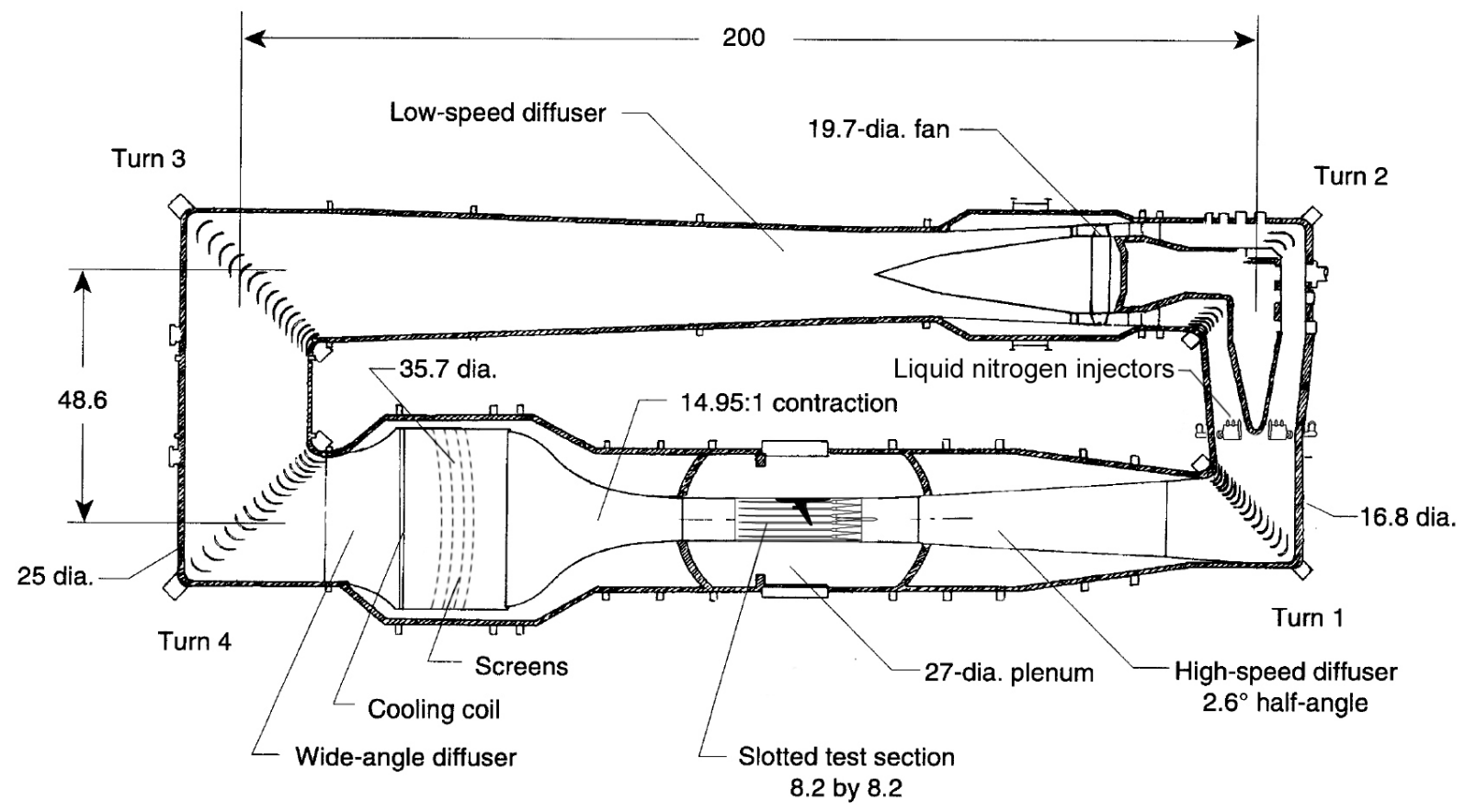

Figure 3. Sketch of the National Transonic Facility tunnel circuit. Linear dimensions are given in feet.

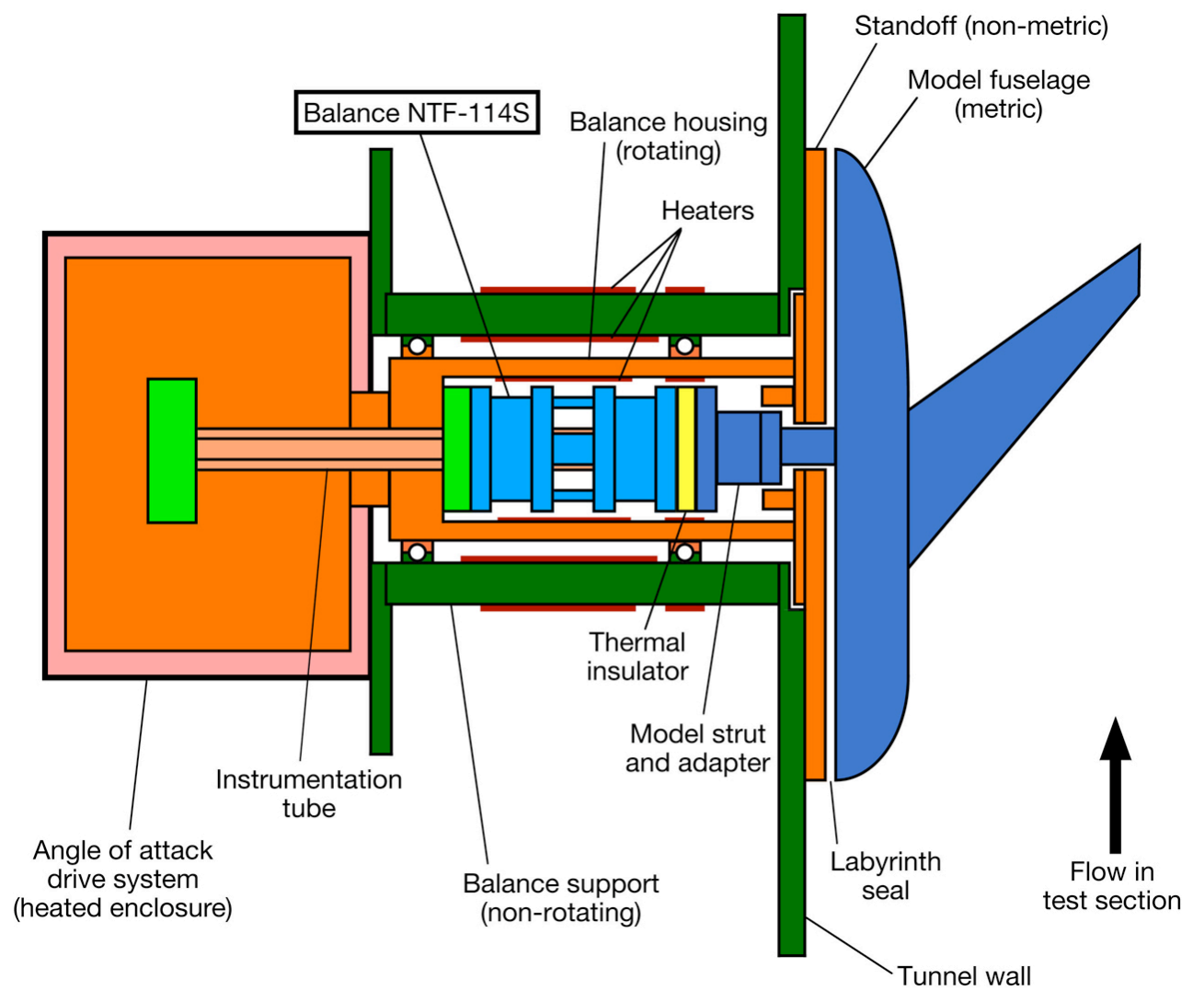

Figure 4. Sketch of sidewall model support system. 

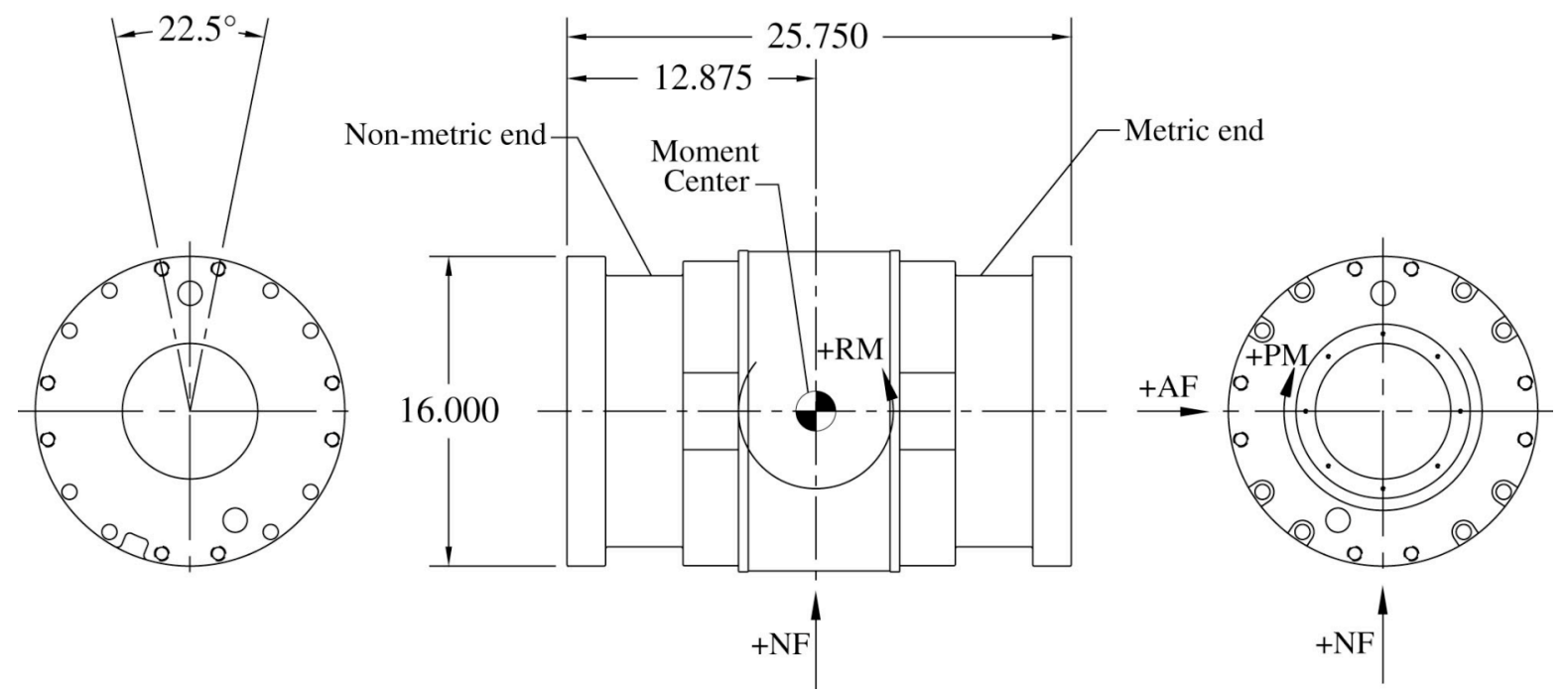

Figure 5. NASA Langley Research Center balance NTF-114S. Linear dimensions are given in inches.

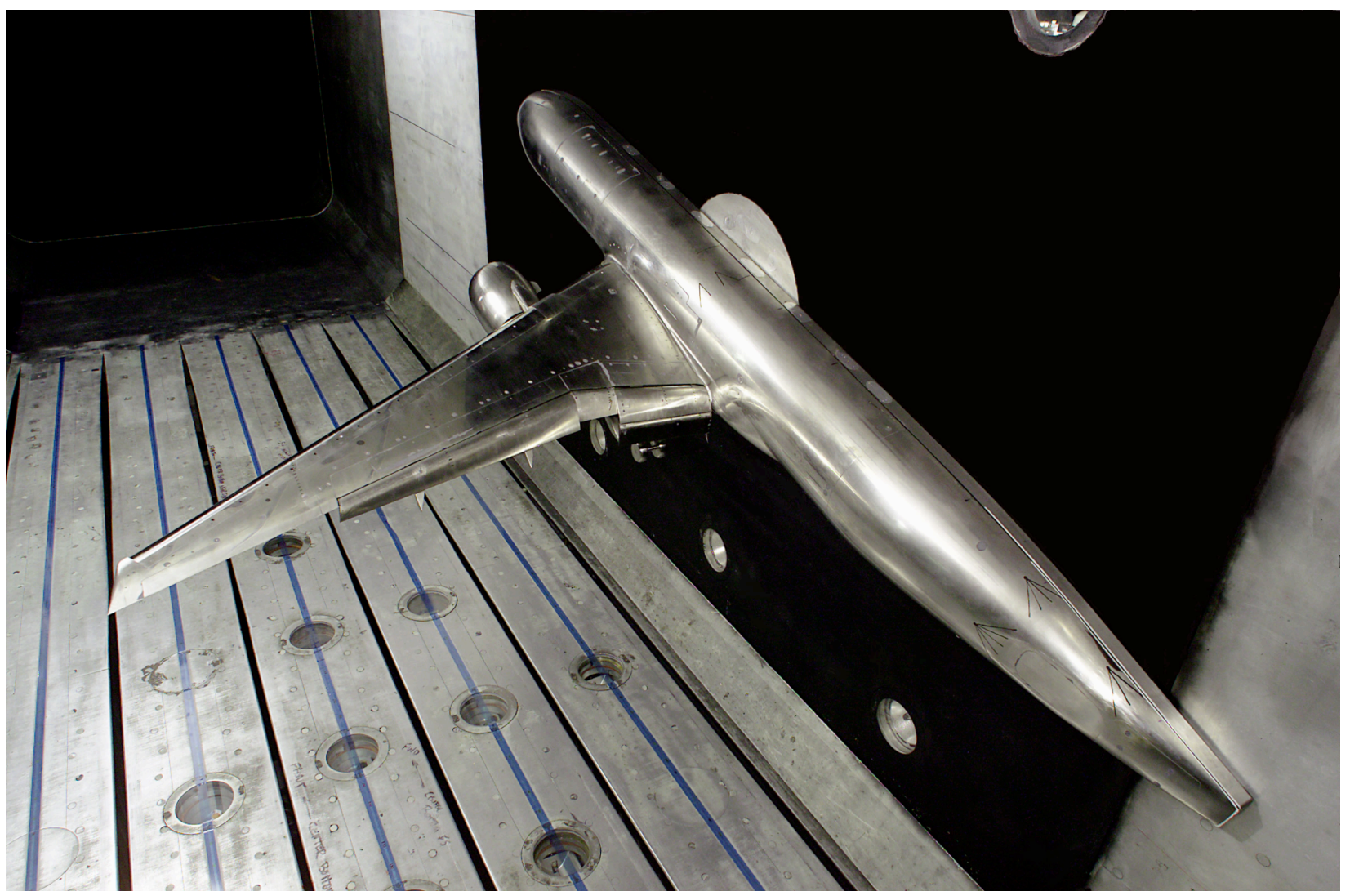

Figure 6. Photograph of a 5.2\% Boeing 777 semi-span model mounted in the NTF. 


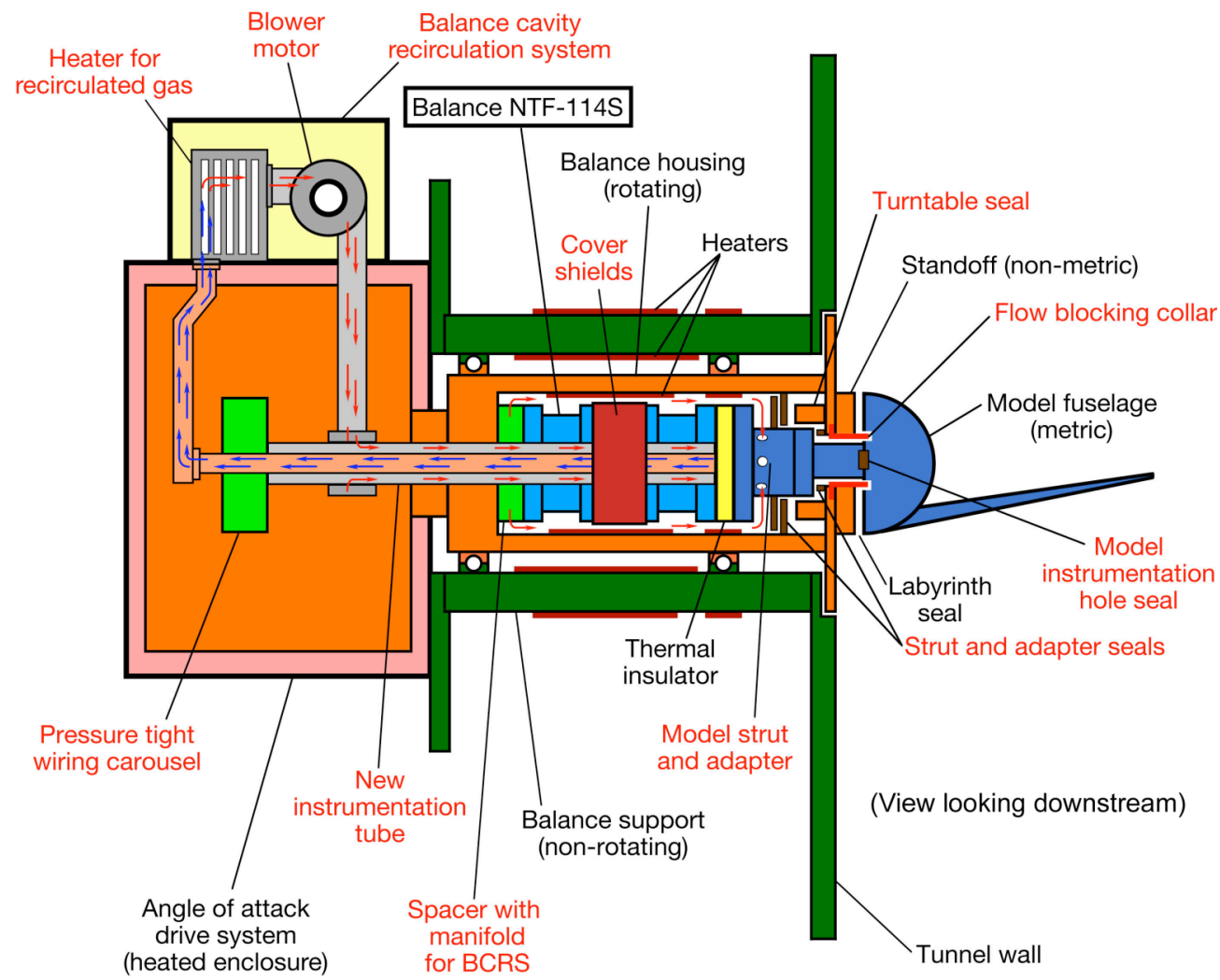

Figure 7. Modifications to the sidewall model support system to improve cryogenic operations.

\begin{tabular}{|cccc|}
\hline Run & $\mathrm{R}_{\mathrm{mac}} \times 10^{-6}$ & $\mathrm{P}_{\mathrm{T}}$, psi & $\mathrm{T}_{\mathrm{T}},{ }^{\circ} \mathrm{F}$ \\
270 & 23.89 & 56.70 & -249.6 \\
271 & 23.91 & 56.70 & -249.8 \\
272 & 23.95 & 56.70 & -250.0 \\
273 & 19.41 & 56.44 & -218.2 \\
274 & 19.40 & 56.44 & -218.1 \\
275 & 14.76 & 56.10 & -168.2 \\
\hline
\end{tabular}

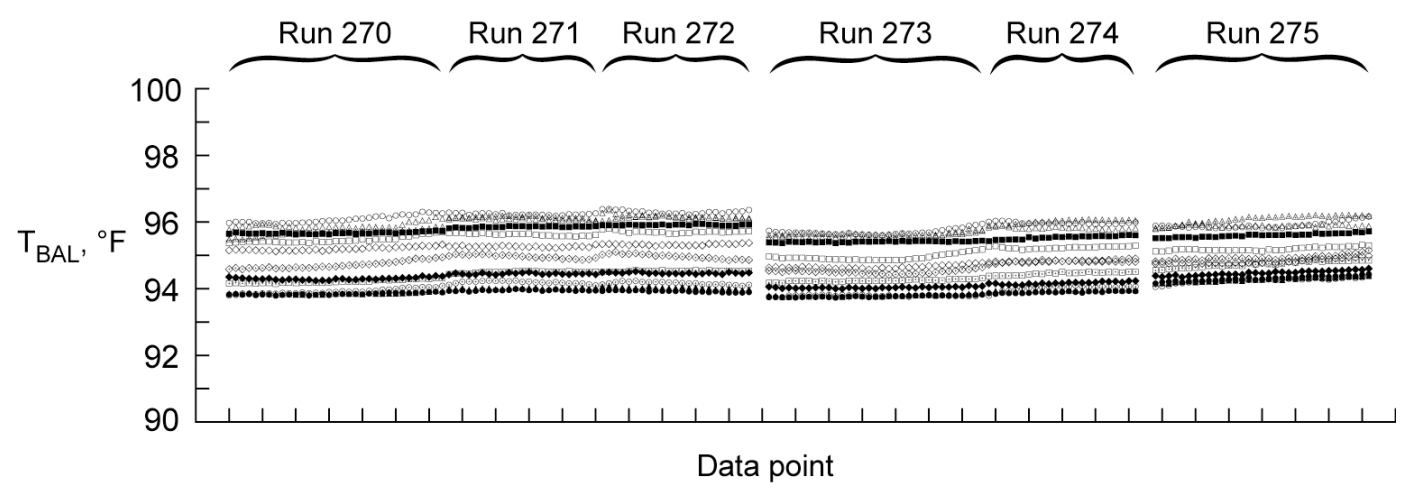

Figure 8. Balance temperature data illustrating the thermal environment of the balance. Landing configuration; $M_{\infty}=\mathbf{0 . 2 1}$. 


\begin{tabular}{|cccc|}
\hline Run & $\mathrm{R}_{\mathrm{mac}} \times 10^{-6}$ & $\mathrm{P}_{\mathrm{T}}, \mathrm{psi}$ & $\mathrm{T}_{\mathrm{T}},{ }^{\circ} \mathrm{F}$ \\
315 & 23.93 & 56.67 & -249.9 \\
316 & 23.89 & 56.67 & -249.7 \\
317 & 23.91 & 56.67 & -249.8 \\
318 & 19.42 & 56.44 & -218.2 \\
319 & 19.41 & 56.44 & -218.1 \\
320 & 14.77 & 56.10 & -168.2 \\
\hline
\end{tabular}

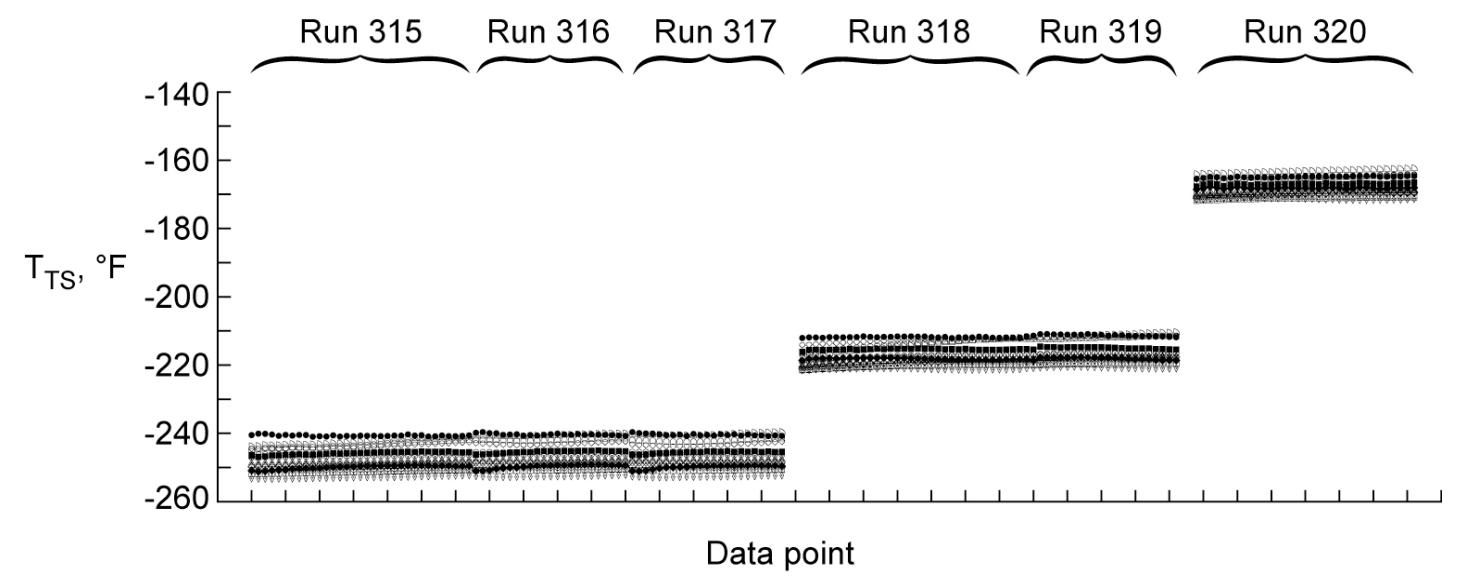

Figure 9. Data illustrating temperature stability through the test section.

Landing configuration; $M_{\infty}=\mathbf{0 . 2 1}$.

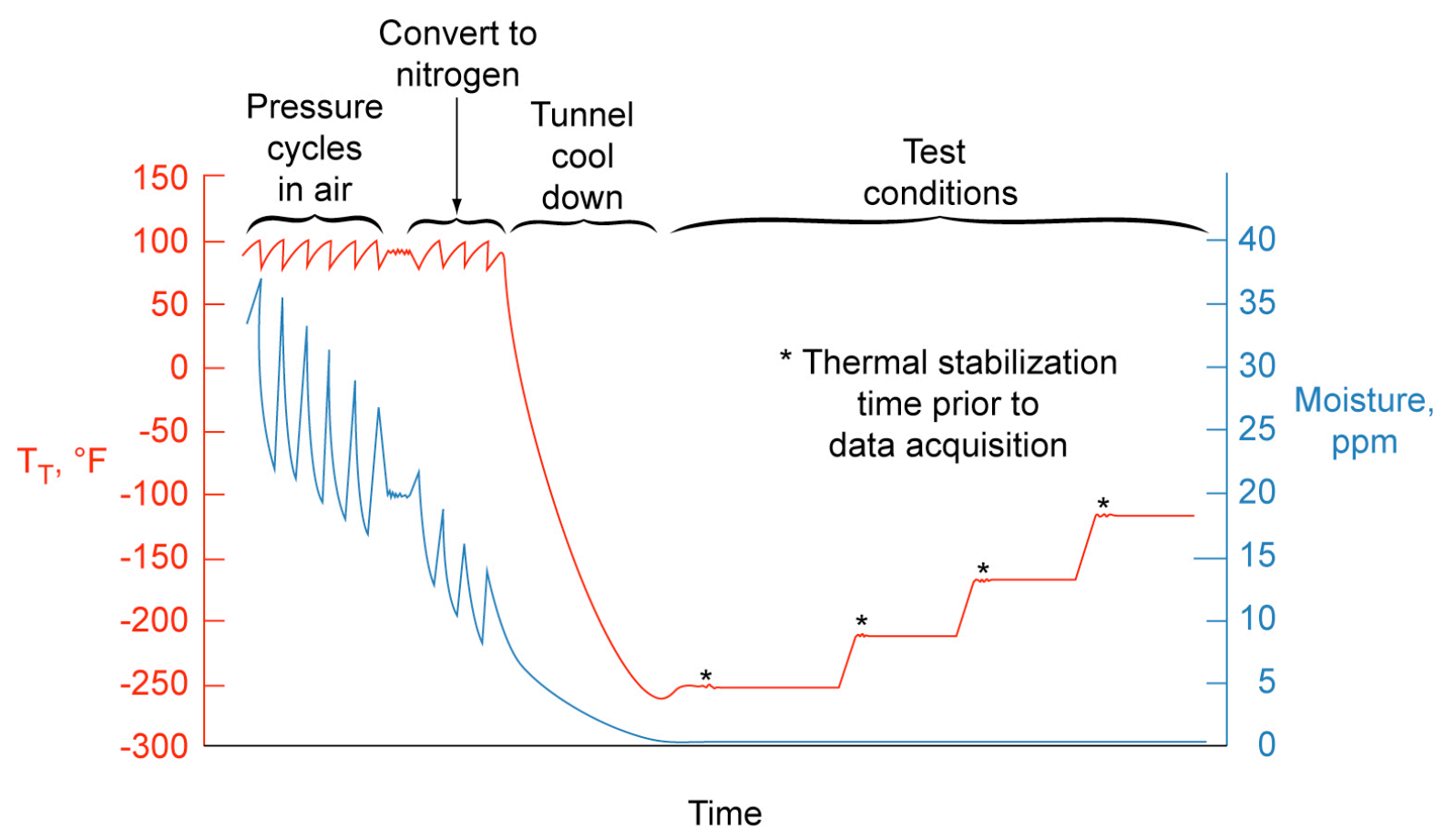

Figure 10. Illustration of moisture management process for cryogenic operations. 


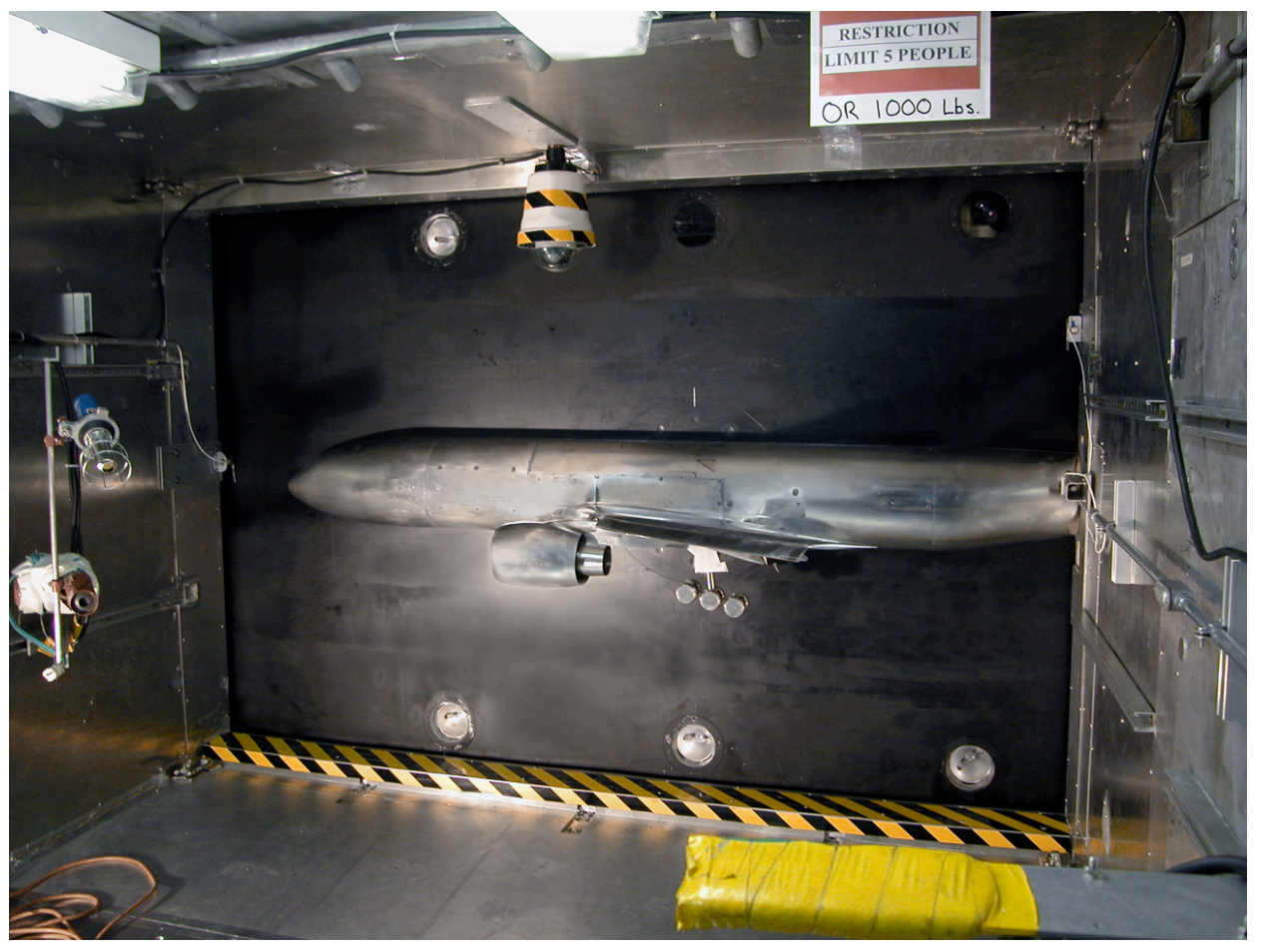

Figure 11. Photograph of modified access housing providing semi-span model access.

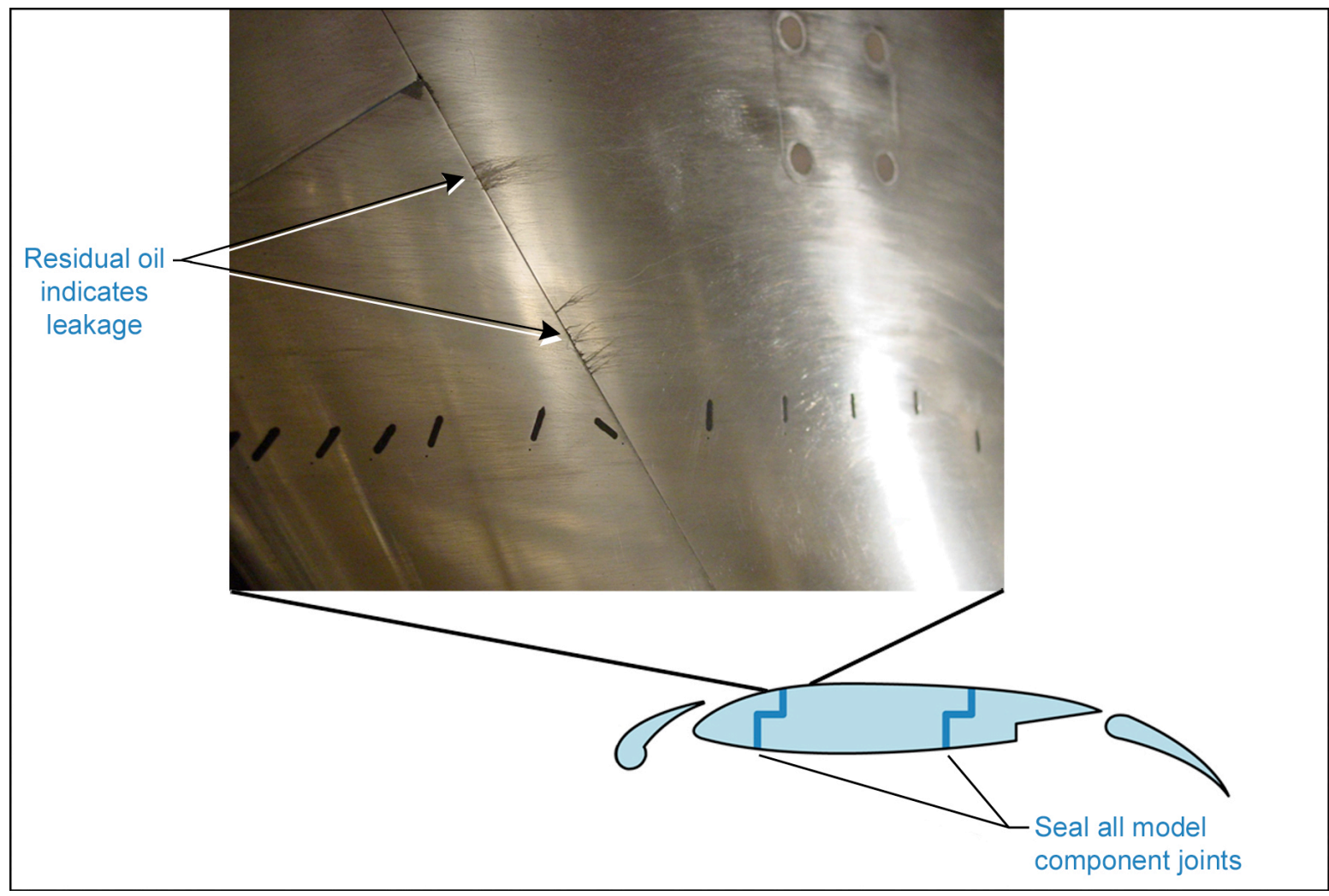

Figure 12. The need for model component sealing. 


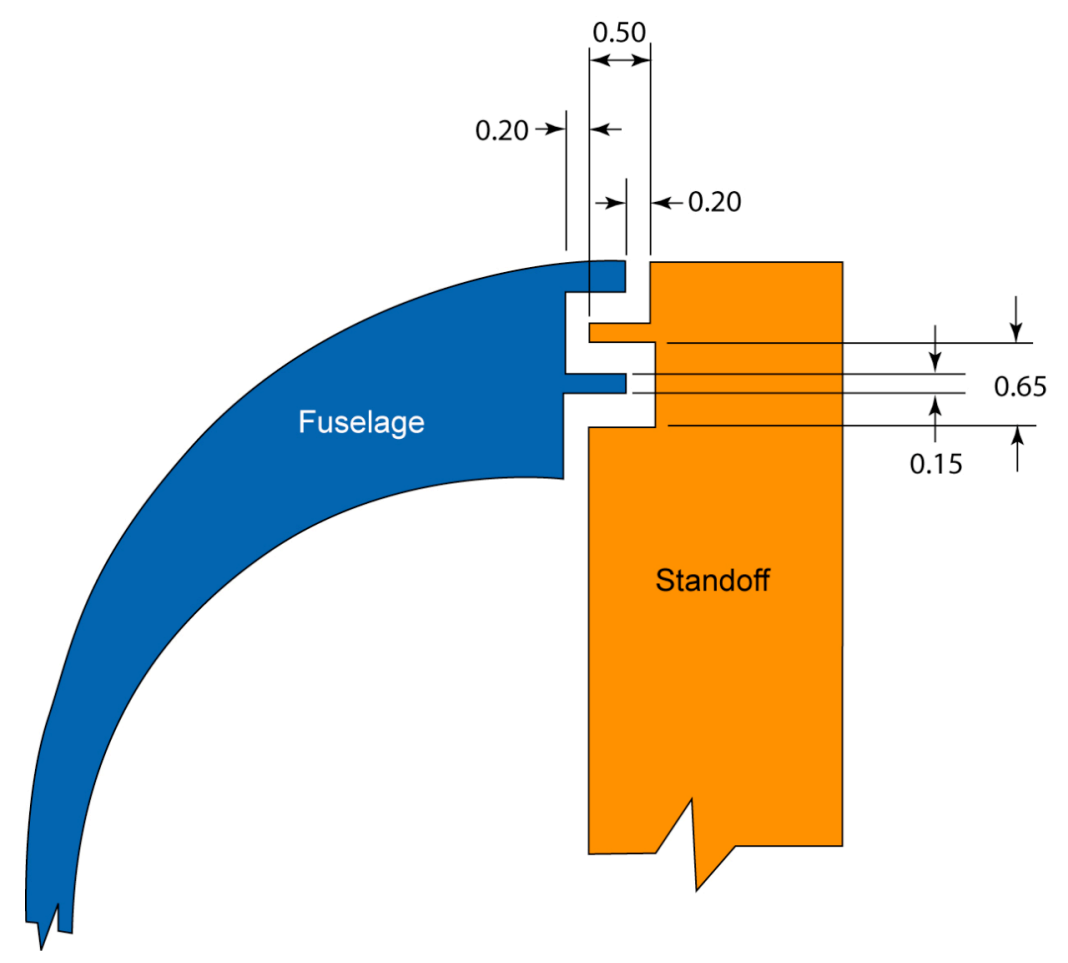

Figure 13. Fuselage-to-standoff labyrinth seal. Dimensions are given in inches.

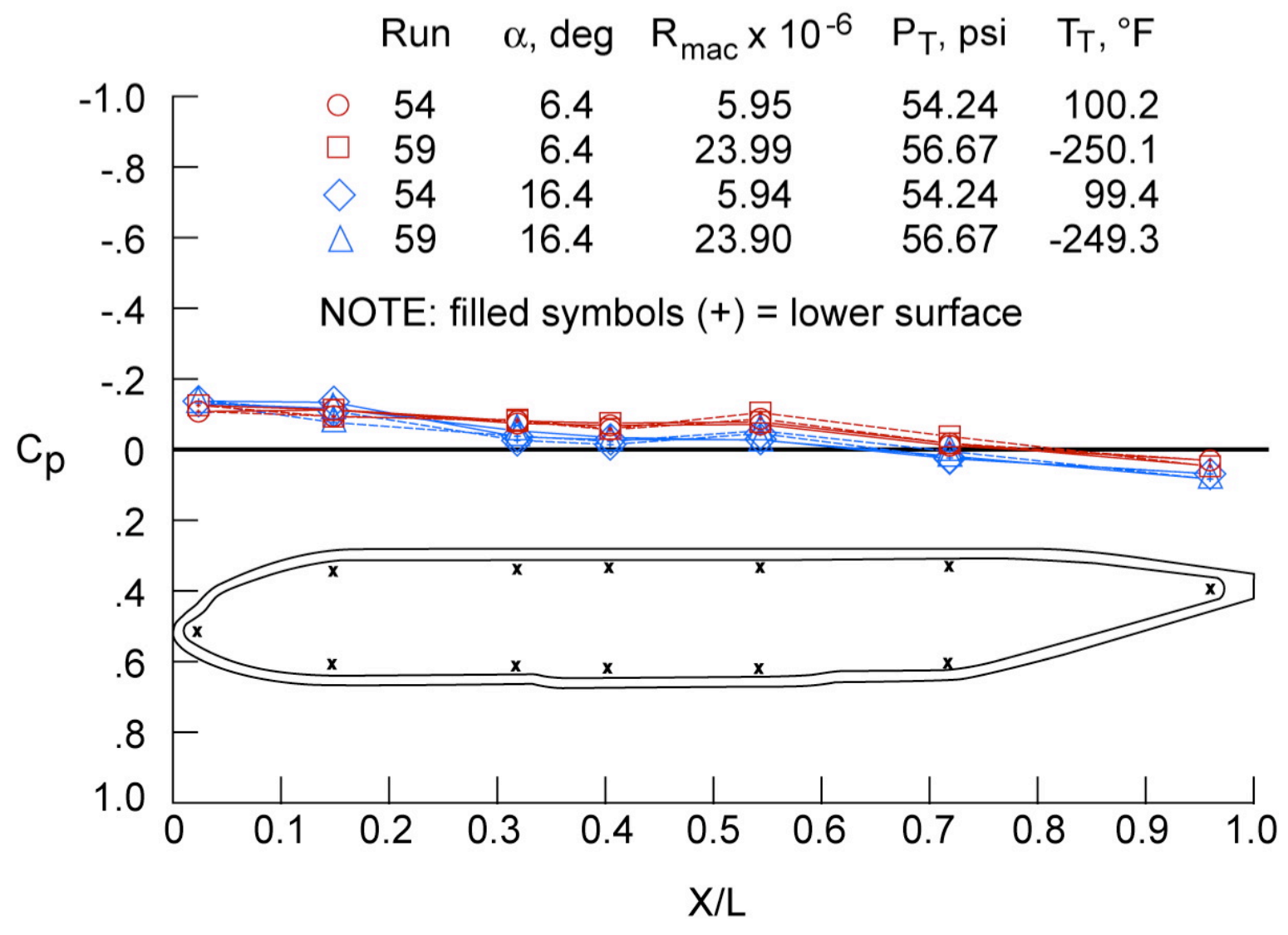

Figure 14. Pressure data inside the fuselage-to-standoff labyrinth seal. Landing configuration; $\mathbf{M}_{\infty}=\mathbf{0 . 2 1}$. 


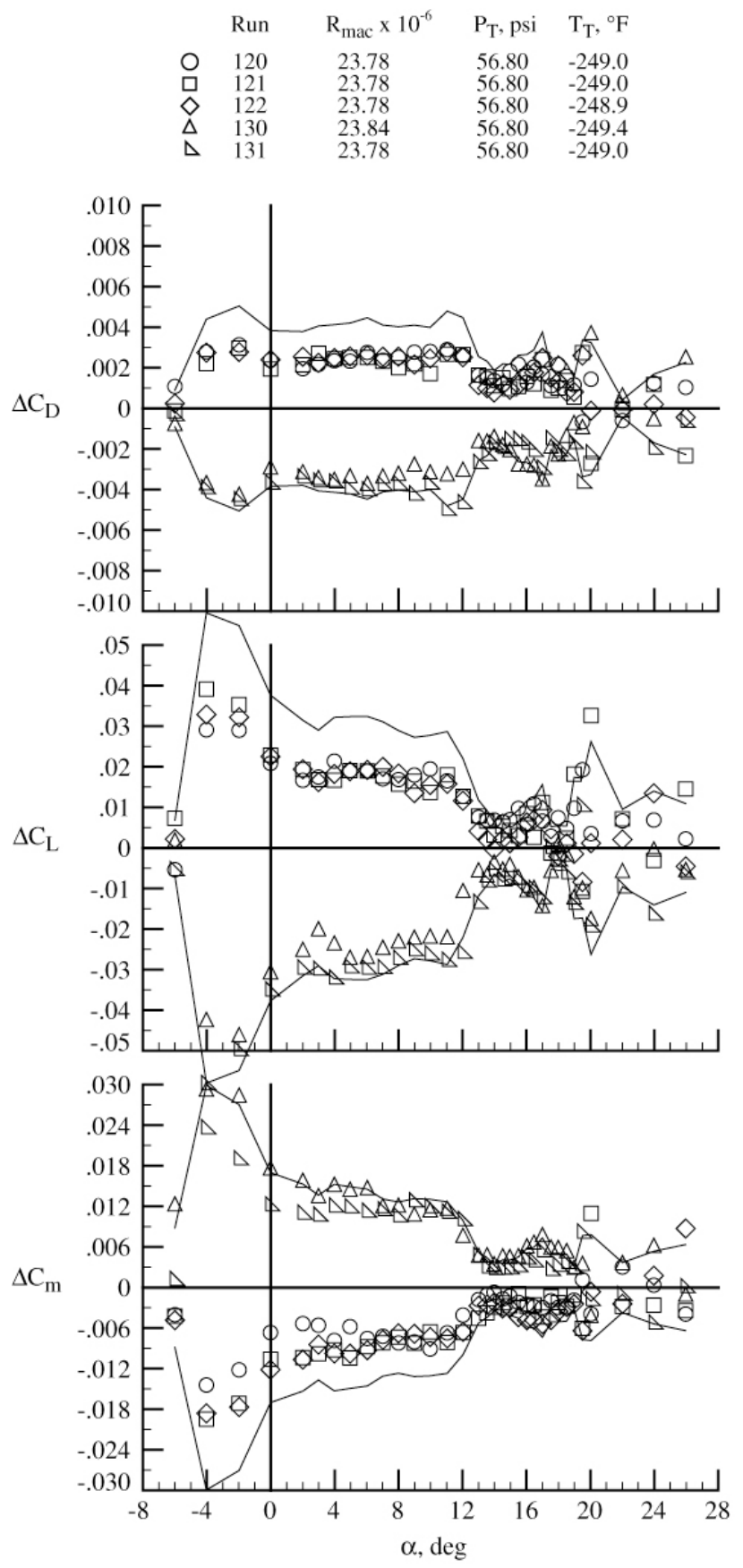

(a) Repeatability data from test 145 .
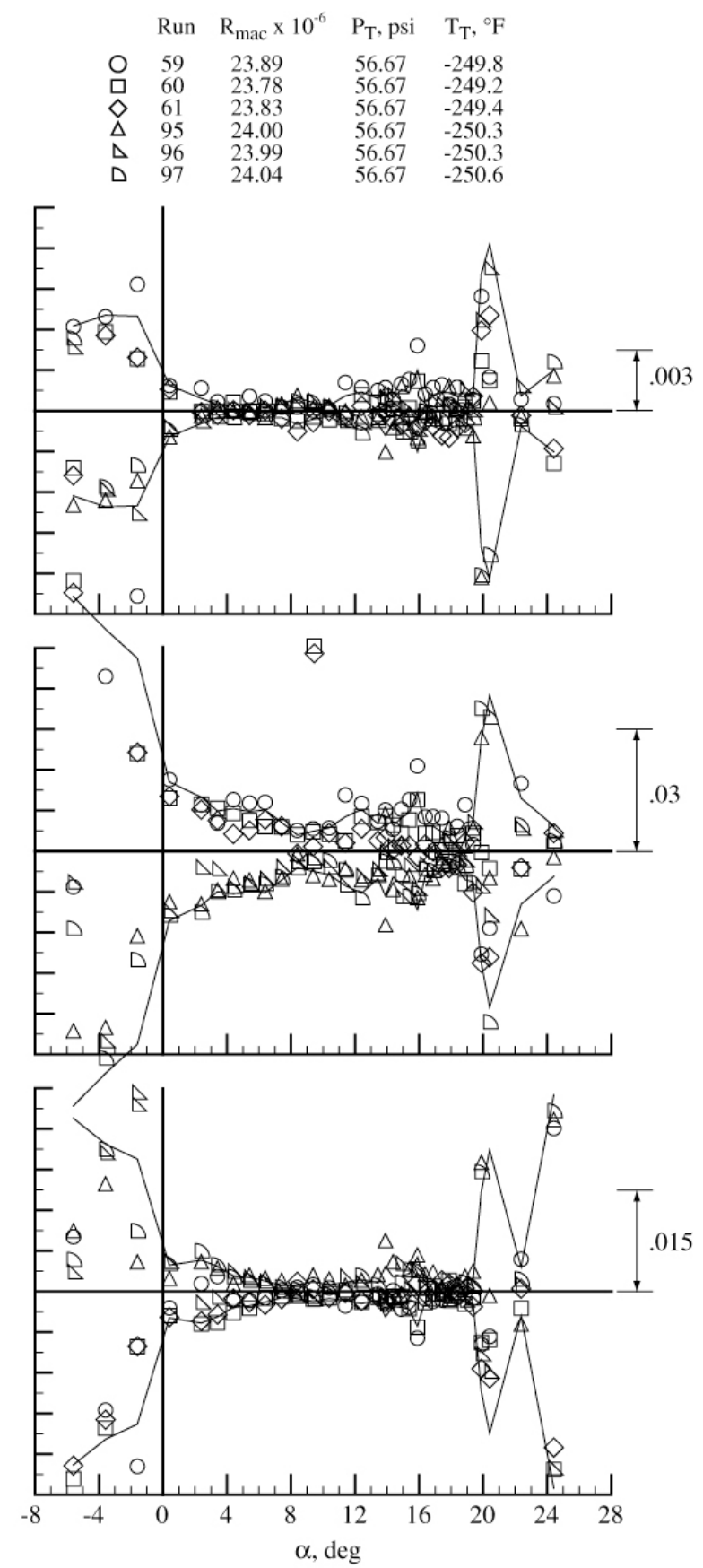

(b) Repeatability data from test 150 .

Figure 15. Comparison of cryogenic data repeatability; solid lines represent $95 \%$ confidence intervals. Landing configuration; $M_{\infty}=0.21$. 


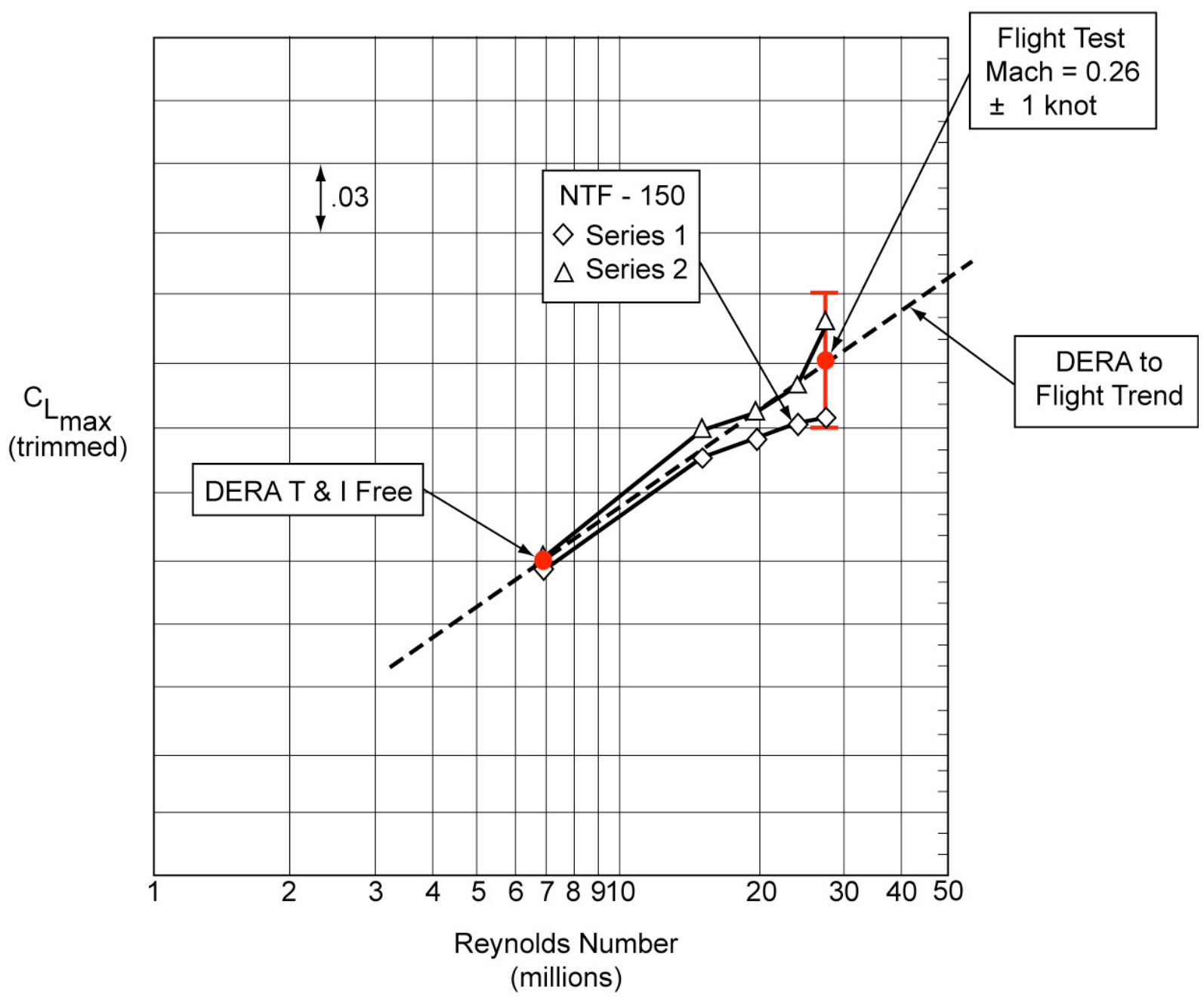

Figure 16. $C_{L \max }$ variation with Reynolds number. Takeoff configuration; $M_{\infty}=0.26 ; q_{\infty} / E=0.087 \times 10^{-6}$. 